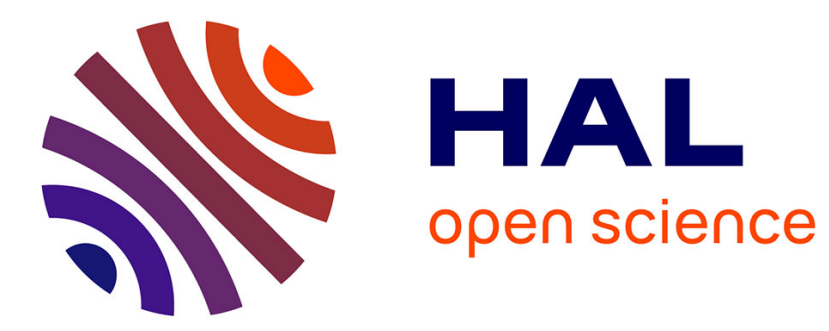

\title{
Innovative design of bismuth-telluride-based thermoelectric micro-generators with high output power
}

S. El Oualid, F Kosior, A. Dauscher, C. Candolfi, G. Span, E. Mehmedovic, J. Paris, B. Lenoir

\section{- To cite this version:}

S. El Oualid, F Kosior, A. Dauscher, C. Candolfi, G. Span, et al.. Innovative design of bismuthtelluride-based thermoelectric micro-generators with high output power. Energy \& Environmental Science, 2020, 13 (10), pp.3579-3591. 10.1039/D0EE02579H . hal-03027363

\section{HAL Id: hal-03027363 https://hal.science/hal-03027363}

Submitted on 27 Nov 2020

HAL is a multi-disciplinary open access archive for the deposit and dissemination of scientific research documents, whether they are published or not. The documents may come from teaching and research institutions in France or abroad, or from public or private research centers.
L'archive ouverte pluridisciplinaire HAL, est destinée au dépôt et à la diffusion de documents scientifiques de niveau recherche, publiés ou non, émanant des établissements d'enseignement et de recherche français ou étrangers, des laboratoires publics ou privés. 


\section{Innovative design of bismuth-telluride-based thermoelectric micro-generators with high output power}

S. El Oualid ${ }^{1}$, F. Kosior ${ }^{1}$, A. Dauscher ${ }^{1}$, C. Candolfi ${ }^{1}$, G. Span ${ }^{2,+}$, E. Mehmedovic ${ }^{2, \perp}$, J. Paris $^{2}$, B. Lenoir ${ }^{1, *}$

${ }^{1}$ Institut Jean Lamour, UMR 7198 CNRS - Université de Lorraine, 2 allée André Guinier Campus ARTEM, BP 50840, 54011, Nancy Cedex, France

${ }^{2}$ Mahle Thermoelektronik GmbH, Duisburg, Germany

${ }^{*}$ Corresponding Author: bertrand.lenoir@univ-lorraine.fr

+ Present address: SAM GmbH\&CoKG, Himmelreichweg 4, A-6112 Wattens, Austria

${ }^{\perp}$ Present address: STAUFFEN.Quality Engineers GmbH, Blumenstraße 5, D-73257 Köngen, Germany

\section{Abstract}

The ever-increasing number of connected objects requires novel ways to power them and make them fully autonomous. In this context, photovoltaic, piezoelectric or thermoelectric energy-harvesting technologies show great promises as they make possible the conversion of solar radiation, motion or thermal energy into useful electricity for charging micro-batteries for instance. Thermoelectric micro-generators ( $\mu$-TEGs) exhibit several key benefits, making them prime candidates for harvesting any temperature difference between their two exchange surfaces. However, their output power critically depends on the design of the $\mu$-TEG, the 
minimization of the detrimental influence of the contact resistances and on the coupling of the $\mu$-TEG with the heat source and heat sink. Here, we theoretically and experimentally demonstrate how these inherent difficulties can be mitigated using an innovative flexible $\mu$ TEG design based on bismuth telluride thin films. Our experimental results show that an output power of $5.5 \mu \mathrm{W}$ per thermocouple can be generated under a temperature difference of only 5 $\mathrm{K}$, in excellent agreement with predictions based on three-dimensional finite element analyses. These remarkable results rank our $\mu$-TEG among the best micro-generators currently available.

\section{Broader context}

Thermoelectric materials can directly convert waste heat into electrical power, offering interesting prospects to power electronic wireless devices when assembled into thermoelectric micro-generators ( $\mu$-TEGs). A broad deployment of this green energy technology relies on the maximum output power generated by the conversion of small temperature differences available around room temperature which itself, critically depends on the architecture of the $\mu$-TEG, the control of the electrical contact resistances between the different material layers and on the coupling of the $\mu$-TEG with its working environment. Here, we show how these inherent difficulties can be mitigated by using an innovative and simple design of the $\mu$-TEG in conjunction with a careful control of the fabrication process. In excellent agreement with threedimensional finite-element analyses, our design enables the fabrication of $\mu$-TEGs able to deliver output powers spanning the range from $\mu \mathrm{W}$ up to $\mathrm{mW}$, depending on the number of thermocouples assembled. Because this range is relevant for a plethora of applications, our work paves the way towards a more widespread use of this technology in various industrial sectors. 


\section{Introduction}

Wireless sensors, which nowadays provide direct information about our environment, see their impact on our society expanding. Their number is expected to grow exponentially with the Internet-of-Things (IoT) paradigm. ${ }^{1}$ In response to the challenges raised by the powering of billions of interconnected electronic devices, an increasing interest in nano- and microelectronic devices self-powered by energy harvesting via thermoelectric (TE) effects has emerged. ${ }^{2-14}$ At the scale of these nomadic micro-devices, TE effects enable directly converting heat into useful electricity. ${ }^{15}$ Because this direct solid-state conversion does not involve any moving parts, the TE technology offers unique advantages in terms of maintenance, lifetime, and scalability to small sizes. A thermoelectric generator (TEG) consists of several thermocouples made of $n$ - and $p$-type semiconducting legs connected electrically in series via metallic conductors and thermally in parallel. ${ }^{15}$ Despite remarkable recent progress in the development of bulk, highly-efficient TEGs and flexible TEGs based on organic compounds, ${ }^{16-}$ 18 a widespread use of this technology is still largely hampered by the low output power achieved due to the detrimental influence of contact resistances and the inherent difficulties in coupling these devices to their working environment. In spite of these limitations, this green technology would provide an elegant way to generate electrical power for low-consumption devices or to act as a complementary energy source for extending batteries lifetime, thereby overcoming the critical issue of the autonomy of the electronic devices. The development of the TE technology for powering micro-systems may benefit from the design of novel architectures of thermoelectric micro-generators ( $\mu$-TEGs) that would mitigate both of the above-mentioned main current limitations and enable using low-cost deposition techniques of the TE materials such as sputtering, ${ }^{19-21}$ screen printing, ${ }^{22-24}$ electrodeposition,,${ }^{25-27}$ or roll-toroll processing. ${ }^{28}$ 
Several $\mu$-TEG architectures for near-room-temperature applications have been fabricated in prior studies (Table S1 in ESI), ${ }^{19,27,29-48}$ and discussed in several reviews. ${ }^{49-51}$ Due to their outstanding thermoelectric properties, the $n$ - and $p$-type thermoelectric legs are mostly composed of $\mathrm{V}_{2}-\mathrm{VI}_{3}$ semiconductors based on $\mathrm{Bi} 2 \mathrm{Te}_{3}$ compounds. ${ }^{16}$ Metals,${ }^{27,46}$ poly-Si1-x $\mathrm{Ge}_{x}$ (Refs. 29-33) and, more recently, organic materials (Refs. 43-45,52) have also been considered, despite their lower intrinsic transport properties. The proposed architectures can be roughly divided into two categories, involving either in-plane or cross-plane configurations (Figure S1 in ESI), depending on the direction of the heat flow through the device. In the inplane configuration, the heat flux is parallel to the substrate, which is preferentially chosen to have a low thermal conductance in order to minimize parasitic heat flows through it. This configuration offers some advantages such as a high output voltage even for low temperature differences owing to the possibility to design longer legs with a high density of thermocouples. It also offers several design strategies to improve the thermal contact to the heat source and to the heat sink. However, the high internal electrical resistance of the legs due to small crosssection area $A$ (typically few $\mu \mathrm{m}^{2}$ ) can be a limiting factor to achieve a high output power. In the cross-plane configuration, the heat flows perpendicularly to the substrates, which should be a high thermal conductor. This architecture is similar to the $\pi$-shaped structure of conventional TEGs but with shorter legs, on the order of few tens or hundreds of $\mu \mathrm{m}$. This configuration allows for a relatively high output power if the electrical and thermal contact resistances and temperature gradients issues are carefully controlled.

Here, we demonstrate how the advantages of both in-plane and cross-plane configurations can be successfully combined using an innovative $\mu$-TEG design (Figure 1a). The structure of the device has an overall vertical, in-plane-configuration but integrates thick films of several tens of $\mu \mathrm{m}$ made of $\mathrm{Bi}_{2} \mathrm{Te}_{3}$-based compounds with large surface area favoring low internal electrical resistance. Conforming to the predictions of three-dimensional finite-element 
analyses, the normalized power density achieved is $\sim 38 \mu \mathrm{W} \mathrm{cm} \mathrm{K}^{-2}$ for a temperature difference of $5 \mathrm{~K}$ around room temperature, that is, one of the highest value reported so far in the literature, despite the low filling rate of the TE elements (Figure 1b). ${ }^{21,23,27-43}$ This novel generation of $\mu$-TEGs operating near room temperature offers an elegant solution for powering sensors in various industrial sectors, such as, e.g., gas pipe monitoring or bearing condition monitoring on trains, two applications where these devices are currently tested. ${ }^{53}$

\section{Design and modelling of the $\mu$-TEG}

\subsection{Design of the $\mu$-TEG}

The architecture of our $\mu$-TEG is based on the TE building block illustrated in Figure 2 a. This structure results from co-laminated thin plates following the sequence copper, polyimide, copper. Polyimide-foil substrates present the advantages of being inexpensive, electrically insulating, highly stable up to $230^{\circ} \mathrm{C}$ and of exhibiting a thermal expansion coefficient similar to that of $\mathrm{Bi}_{2} \mathrm{Te}_{3}$-based materials near room temperature. Of note is the shape of the active legs that exhibit a wavy form, instead of the cuboid form generally encountered in conventional TEG designs. It thus favors achieving a high surface and hence, a low internal electrical resistance. The bottom copper layer is also etched on its entire width in order to create a gap that decouples the two copper layers from each other both electrically and thermally. Copper rivets are used to ensure a good electrical and thermal connection between the bottom and top copper plates and allow for the current to flow in the structure.

When a heat source and a heat sink are connected to the copper parts (Figure 2b), a temperature difference will appear on the thermoelectric legs resulting in a voltage according to the Seebeck effect. Multi-unit modules can be advantageously built by putting several of 
these basic units connected thermally in parallel and electrically in series so as to be able to adjust the output power for a specific application (Figure 2c).

\subsection{Modelling and parameters}

Thermoelectric effects (Seebeck, Peltier and Thomson effects) are defined by the coupling of the heat $(\vec{q})$ and current $(\vec{J})$ flows through a material following the two generalized Ohm and Fourier laws expressed, for an isotropic material, as ${ }^{15,54,55}$

$$
\begin{gathered}
\vec{q}=\pi \vec{J}-\kappa \vec{\nabla} T \\
\vec{J}=\sigma \vec{E}+\sigma \alpha \vec{\nabla} T
\end{gathered}
$$

where $\vec{E}$ is the electric field that derives from the potential $V(\vec{E}=-\vec{\nabla} V), \vec{\nabla} T$ is the temperature gradient, $\pi$ is the Peltier coefficient, $\kappa$ is the total thermal conductivity, $\sigma$ is the electrical conductivity and $\alpha$ is the thermopower (or Seebeck coefficient).

In a stationary state, the local energy balance and charge conservation can be expressed by the two equations

$$
\begin{gathered}
\vec{\nabla} \cdot \vec{q}=\vec{E} \vec{J} \\
\vec{\nabla} \cdot \vec{J}=0
\end{gathered}
$$

This set of partial differential equations, combined with Eq.(1) and Eq.(2), can be solved numerically by finite-element analyses to determine the temperature and electrical potential distributions in the materials. Herein, these equations were solved numerically in three dimensions using the Comsol Multiphysics software under specific boundary conditions. The structure of the device was constructed and the meshing was optimized to reduce the calculation time without degrading the accuracy of the results (see e.g. Figure S2 in ESI). The physical 
properties of the $\mathrm{Bi}_{2} \mathrm{Te}_{3}$-related compounds constituting the active $n$ - and $p$-type elements, the polyimide and the copper plates used in these calculations are listed in Table S2 in the ESI file. Their transport properties were assumed to be isotropic and temperature independent considering the limited temperature difference applied (between 1 and $10 \mathrm{~K}$ ). Within this last approximation, the Thompson effect is thus cancelled. The electrical characteristics were calculated by connecting the basic unit to an external load resistance $R_{\text {load }}$. The values of $R_{\text {load }}$ were varied to determine the voltage $U$ - current $I$ curves, from which the power $P$ delivered by the load (that is, the output power) can be calculated by $P=U I$. The function $U(I)$ can be written as

$$
U(I)=\left(\alpha_{p}-\alpha_{n}\right) \Delta T(I)-R I
$$

where $R$ is the internal resistance of the TEG.

Assuming boundary conditions where the temperatures at the cold and hot sides are fixed (so that $\Delta T(I)$ is constant), $U$ evolves linearly with $I$ so that $R$ can be directly extracted from the slope of the $U(I)$ line. Using a simple steady-state, one-dimensional heat transfer analysis, ${ }^{16-18}$ the maximum output power $P_{\max }$ for one conventional thermocouple $(\pi$-shaped structure) of same length $L$ and cross-section area $S_{T E}$ submitted to a fixed temperature difference $\Delta T$ is given by ${ }^{15,54,55}$

$$
P_{\max }=\frac{\left(\alpha_{p}-\alpha_{n}\right)^{2} \Delta T^{2}}{4 R}=\frac{S_{T E}\left(\alpha_{p}-\alpha_{n}\right)^{2} \Delta T^{2}}{4 L\left(\rho_{p}+\rho_{n}\right)}
$$

where $\alpha_{i}$ and $\rho_{i}$ are the thermopower and the electrical resistivity of the leg $i=n, p$, respectively. Eq.(6) is valid when the electrical and thermal contact resistances are neglected and when the 
device is connected to an external load $\left(R_{\text {load }}\right)$ matching the internal resistance $\left(R=\frac{L\left(\rho_{p}+\rho_{n}\right)}{S_{T E}}\right)$ of the thermocouple. Taking into account the geometrical parameters of our $\mu$-TEG, Eq.(6) can be approximated as

$$
P_{\text {max }} \approx \frac{S_{T E}\left(\alpha_{p}-\alpha_{n}\right)^{2} \Delta T^{2}}{4 m\left(\rho_{p}+\rho_{n}\right)}
$$

with the surface area $S_{T E} \approx L_{\text {copper }} h_{\text {copper }}\left[1+\frac{2(e-m)}{(a+b)}\right]$.

Using different boundary conditions, the temperature difference on the TE elements will depend on $I$, because the hot and cold temperatures on the TE elements are not only function of the thermal resistance of the TE elements but also on the Joule and Peltier effects that depend on $I$. The pertinence of our approach was first tested on a conventional TEG with a $\pi$-shaped geometry with fixed temperatures on both ends. Our results were in excellent agreement with calculations performed using well-established analytical modelling assuming fixed temperature difference (hereafter called the ideal model), ${ }^{15,54,55}$ thereby validating our numerical finiteelement modelling.

The optimization of the electrical performances of a TEG is a complicated task, depending intimately on the boundary conditions related to the intended application and its environmental working conditions, especially the available heat sources and sinks, the thermal interface materials, and the parasitic heat losses. ${ }^{51}$ Thus, for a typical thermoelectric system with heat sinks mounted on the hot and cold sides of the thermoelectric module, the systemlevel design and optimization are of paramount importance. The designer has the choice between optimizing either the efficiency or the output electrical power. In thermoelectric energy harvesting, an infinite and free heat source can be assumed to be available so that the desirable quantity to optimize is rather the output electrical power. In this approach, two scenarios may 
occur, that is, either a temperature limitation due to a low thermal resistance of the environment (in industrial applications for instance) or a heat flow limitation due to a high thermal resistance of the environment (body heat for instance, Ref. 44).

In the next section, we will focus first on models taking into account boundary conditions with a fixed temperature difference applied to our novel design of $\mu$-TEG. These conditions, considered as ideal, will enable getting a general idea of the electrical performances of the proposed novel design. We will then move to more realistic conditions, considering a constant temperature applied to the hot side while a convective heat transfer occurs between the cold side of the TEG and the environment. In both cases, the influence of radiations within the TE module is assumed to be insignificant due to the low temperature differences studied.

\section{Three-dimensional finite-element analyses of the $\mu$-TEG}

\subsection{Fixed boundary conditions}

In order to simplify the numerical study of our complex design, we first consider only one $n-p$ thermocouple without any additional layers, such as, e.g., a diffusion barrier. The structure was parameterized using several geometrical parameters (see Figure S3 in the ESI). As a starting point, arbitrary values of these different parameters were chosen (Figure S3c in the ESI). Among them, the length of the TE materials determined by the parameter $m$ (see Figure $2 \mathrm{a}$ ), the period $(a+b)$, the parameter $e$ (for fixed boundary conditions, this parameter and $l_{\text {gap }}$ are equivalent) and the electrical contact resistance $\rho_{c}$ were found to be the key parameters that mostly govern the maximum output power $P_{\max }$ of the device (see Eq.(7)). Hereafter, we will therefore focus on these parameters. 
Keeping constant the cold side temperature $T_{c}$ to $300 \mathrm{~K}$ (that is, the lower copper parts, see Figure 2), three different hot side temperatures $T_{h}=301,305$ and $310 \mathrm{~K}$ were considered. These values, which are equivalent to temperature differences of 1,5 and $10 \mathrm{~K}$, are those typically considered in power generation applications near room temperature. The spatial variations of the distribution profiles of temperature and electrical potential, computed under open circuit conditions, are similar regardless of the temperature difference imposed (Figure 3). Interestingly, due to the excellent electrical and thermal properties of copper, the $\mathrm{Cu}$ surfaces remain equipotential and isothermal. Because the dimensions of the active TE parts are small, both isothermal and equipotential lines in the upper part of the thermocouple closely follow the wavy shape of the TE parts in the legs. As the charge and heat fluxes are perpendicular to the equipotential and isothermal lines, respectively, their field can be easily deduced (Figure S4 in ESI). In the bottom part of the thermocouple, the polyimide, which contributes to the heat transfer, breaks the symmetry by slightly perturbing this representation. This can be visualized by the slightly deformed equipotential and isothermal lines with respect to those of the upper part. Nevertheless, these deformations remain very small for the three temperature differences considered. Thus, these results demonstrate that, as a first approximation, the wavy shape can be replaced by an equivalent band of the same length, the surfaces of which would be subjected to the cold and hot side temperatures (Figure S5 in the ESI). This equivalence simplifies the modelling of this design and suggests that the numerical results should approach the results obtained by considering the ideal model for fixed temperatures.

For each temperature difference, the $U(I)$ curve and the output power $P$ of the $\mu$-TEG were calculated (Figure 4). The results evidence that $P_{\max }$ is obtained when the impedance matching condition is realized, that is, when $s=R_{\text {load }} / R=1 . P_{\max }$ is on the order of $3.2 \mu \mathrm{W}$ for $\Delta T=1 \mathrm{~K}$ and significantly increases with increasing the temperature difference to reach values ranging between 80 and $300 \mu \mathrm{W}$ for $\Delta T=5$ and $10 \mathrm{~K}$, respectively. This increase is 
consistent with the ideal model which indicates that $P_{\max }$ follows a $\Delta T^{2}$ dependence (see Eq.(7)).

The slope of the $U(I)$ curve obtained for $\Delta T=1 \mathrm{~K}$ results in an internal resistance of 5 $\mathrm{m} \Omega$ per thermocouple. This value, small compared to the results reported in the literature, ${ }^{19,27,29-}$ ${ }^{46}$ originates from the large surface area covered thanks to the undulated shape of the TE part. As expected, the $U(I)$ curves calculated for $\Delta T=5$ and $10 \mathrm{~K}$ exhibit similar slopes since the electrical properties can be considered as temperature-independent between 300 and $310 \mathrm{~K}$.

With fixed temperature boundary conditions, the maximum output power can be made arbitrarily large by varying the $\mu$-TEG's architecture parameters. Since our structure conforms to the ideal model as a first approximation, it is clear from Eq.(7) that reducing the electrical resistance $R$ of the thermocouple will increase the electrical power. In this context, a reduction of the parameter $m$ (length of the legs) or an increase in the contact surface with copper (that is, a reduction in the period $(a+b)$ assuming that $l_{\text {gap }}$ or, equivalently, $e$, is constant) should lead to an improvement of the electrical performance. The numerical results, obtained for $\Delta T=$ $1 \mathrm{~K}$ and for two different values of $m$ and $(a+b)$ confirm this scenario (see Figure S6 in the ESI). A decrease in $m$ or $(a+b)$ results in an increase in the electrical power. However, it is not worthwhile discussing further the benefits of reducing the length $m$ or the period $(a+b)$ without incorporating deleterious and parasitic effects that are always present in real $\mu$-TEGs.

One essential aspect when developing $\mu$-TEGs is the presence of an electrical contact resistance $\rho_{c}$ that inevitably reduces the maximum output power of the device (the total resistance $R$ in Eq. (7) becomes $\frac{\left(\rho_{\mathrm{p}}+\rho_{\mathrm{n}}\right) L}{S_{T E}}+\frac{4 \rho_{c}}{S_{T E}}$, if we assume that the contact resistance is the same at the cold and hot sides for both the $n$ - and $p$-type legs). In order to determine its influence on $P_{\text {max }}$, simulations were carried out with $\rho_{c}$ varying between $10^{-8}$ and $10^{-4} \Omega . \mathrm{cm}^{2}$. These lower and upper bounds correspond to perfectly-controlled and poor-quality contacts, 
respectively. For $\Delta T=1 \mathrm{~K}$ and keeping the parameters defined in Figure $\mathrm{S} 2$, the results show that $P_{\text {max }}$ rapidly decreases with increasing $\rho_{c}$ from $3.2 \mu \mathrm{W}$ for $\rho_{c}=10^{-8} \Omega \mathrm{cm}^{2}$ to $0.3 \mu \mathrm{W}$ for $\rho_{c}=10^{-4} \Omega \mathrm{cm}^{2}$ (Figure 5). $P_{\max }$ remains nevertheless appreciable $(>1 \mu \mathrm{W})$ when the contact resistance is on the order of $10^{-5}$ to $10^{-6} \Omega \mathrm{cm}^{2}$. Because the additional electrical resistance $R_{C}$ induced by these imperfect contacts is inversely proportional to the total surface area $S_{T E}$ between the TE part and the copper surfaces $\left(R_{C}=4 \rho_{c} / S_{T E}\right)$, the designed wavy shape of the TE part helps to significantly limit its detrimental effect.

\subsection{Mixed boundary conditions}

In most applications near room temperature, the TE converter does not exhibit a fixed temperature at the cold side but rather operates under heat flux conditions. More-realistic performances of the $\mu$-TEG were thus calculated using mixed boundary conditions, that is, the temperature of the hot side is fixed while the heat at the cold side is rejected from the copper parts convectively to the environment (see Figure S7 in the ESI for the boundary conditions).

As a first step, we determined the influence of the heat transfer coefficient $h_{e x}$ at the cold side of the $\mu$-TEG on $P_{\max }$. The different values of $h_{e x}$ considered in this study span the range going from $5 \mathrm{~W} \mathrm{~m}^{-2} \mathrm{~K}^{-1}$, corresponding to natural air convection, up to $400 \mathrm{~W} \mathrm{~m}^{-2} \mathrm{~K}^{-1}$ that corresponds to natural water convection. Moreover, the hot side temperature $T_{h}$ and the temperature of the environment $T_{\infty}$ were kept constant to 305 and $300 \mathrm{~K}$, respectively. The results show that $P_{\max }$ increases when $h_{e x}$ increases due to the increase in the temperature difference on the TE materials resulting from the decrease in the cold side temperature (Figure S8 in the ESI). If we consider the specific case for which the environment is air $\left(h_{e x} \approx 5 \mathrm{~W} \mathrm{~m}^{-}\right.$ ${ }^{2} \mathrm{~K}^{-1}$ ), the temperature difference achieved on the legs is only $0.02 \mathrm{~K}$, that is, less than $1 \%$ of the applied temperature difference of $5 \mathrm{~K}$. This strongly limits $P_{\max }$ that drops from $80.5 \mu \mathrm{W}$ 
in the ideal situation $(\Delta T=5 \mathrm{~K})$ to only $0.01 \mu \mathrm{W}$. The TE materials operate in a regime limited by the thermal sink, ${ }^{56,57}$ for which the temperature drop across the heat sink is higher than that undergone by the TE materials due to the mismatch between the thermal resistance of the thermocouple $\left(1 \mathrm{~K} \mathrm{~W}^{-1}\right)$ and that of the heat $\operatorname{sink}\left(2000 \mathrm{~K} \mathrm{~W}^{-1}\right.$ for a surface of $\left.1 \mathrm{~cm}^{2}\right)$. As we will see below, this problem can be easily mitigated by increasing the exchange surface area $S_{\text {ex }}$ of the $\mu$-TEG.

A fundamental difference between these mixed boundary conditions and the fixed conditions considered previously lies in the fact that the impedance matching condition to reach $P_{\max }$ no longer holds (that is, for fixed boundary conditions, the internal resistance of the thermocouple should match the load resistance, expressed via $s=R_{\text {load }} / R=1$ ). As shown in Figure 6, mixed conditions impose that $s>1$ to reach $P_{\text {max }}$. In such a case, the current value $I$ is lower than that determined for fixed boundary conditions. This variation originates from the interdependence of $s$ and $I$ in the circuit, which alters the Peltier and Joule heats and hence, $\Delta T$.

Under mixed boundary conditions, the length $m$ of the TE materials also influences $P_{\text {max }}$. As shown in Figure 7, $P_{\max }$ evolves with both $m$ and $h_{e x}$ in a non-linear manner. For $h_{e x}=$ $400 \mathrm{~W} \mathrm{~m}^{-2} \mathrm{~K}^{-1}$ (natural water convection), the optimal length is about $0.4 \mathrm{~mm}$ yielding an appreciable value of $P_{\max }=7.5 \mu \mathrm{W}$ per thermocouple. $P_{\max }$ decreases upon decreasing $h_{e x}$ to reach 3.7 and $0.5 \mu \mathrm{W}$ per thermocouple for $h_{e x}=200$ and $40 \mathrm{~W} \mathrm{~m}^{-2} \mathrm{~K}^{-1}$, respectively. As $h_{e x}$ decreases, the optimum length of the thermoelectric layers increases and ranges between 0.6 and $0.9 \mathrm{~mm}$ for $h_{e x}=200$ and $40 \mathrm{~W} \mathrm{~m}^{-2} \mathrm{~K}^{-1}$, respectively. The degradation of the electrical performances is induced by a decrease in $\Delta T$ as a result of the increase in the thermal resistance of the heat sink when $h_{e x}$ decreases.

These results can be qualitatively explained using our above-mentioned equivalence (see Figure S5 in the ESI). Considering the energy balance at the cold side and assuming that the 
Fourier heat is the most important contribution, it can be shown that $\Delta T$ varies as a function of $m$ according to:

$$
\Delta T(m)=T_{h}-T_{c} \approx \frac{h_{e x} S_{e x}\left(T_{h}-T_{\infty}\right)}{h_{e x} S_{e x}+\frac{\lambda S_{T E}}{m}}
$$

From this relation, and assuming that $R_{\text {load }} \approx R$ as a first approximation, the optimum $m$ value maximizing $P_{\max }$ is given by $m_{\text {optimum }} \approx \frac{\lambda S_{T E}}{h_{e x} S_{e x}}$ yielding $\Delta T_{\text {optimum }} \approx \frac{\left(T_{h}-T_{\infty}\right)}{2}$. The first relation indicates that the optimum length of the TE materials not only depends on their thermal properties but also on the efficiency of the heat sink through $h_{e x}$. For a given heat sink, the length of the leg can be resized to maximize the output power. However, under these conditions, the maximum temperature difference achieved on the TE materials with optimized length represents only $50 \%$ of the difference between the temperature of the hot source $T_{h}$ and the temperature of the environment $T_{\infty}$. Hence, assuming perfect electrical contacts, $P_{\max }$ is reached when the thermal impedance matching between the thermocouple and the heat sink is achieved. As shown in Table 1, the results obtained by this simple model are in good agreement with our numerical simulations.

As in the case of fixed boundary conditions, a poor control of the electrical contact resistances further weakens $P_{\max }$. Taking $h_{e x}=400 \mathrm{~W} \mathrm{~m}^{-2} \mathrm{~K}^{-1}, T_{h}=305 \mathrm{~K}, T_{\infty}=300 \mathrm{~K}$ and $\rho_{c}$ values of $10^{-7}, 10^{-5}$ and $10^{-4} \Omega \mathrm{cm}^{2}$, the results (Figure 8 ) indicate that $P_{\max }$ is hardly modified by good-quality contacts $\left(\rho_{c}=10^{-7} \Omega \mathrm{cm}^{2}\right)$ with respect to the ideal case of no contact resistance. However, when $\rho_{c}$ increases to $10^{-5}\left(10^{-4} \Omega \mathrm{cm}^{2}\right), P_{\max }$ decreases by $35 \%(72 \%)$ and the optimal length $m$ increases by $20 \%$ (50\%). Moreover, the temperature difference on the TE materials decreases when $\rho_{c}$ increases $\left(\Delta T=1.4 \mathrm{~K}\right.$ for $\left.\rho_{c}=10^{-4} \Omega \mathrm{cm}^{2}\right)$. The difference between these calculations and the above-mentioned simple relations stems from the fact that 
the contact resistance is no longer proportional to $m$ which modifies the values of $m_{\text {optimum }}$ and $\Delta T_{\text {optimum }}$.

Thanks to these various, yet important considerations, the geometry of the thermocouple can be optimized using the COBYLA method implemented in Comsol Multiphysics, for both types of boundary conditions. As an example, taking $\rho_{c}=10^{-5} \Omega \mathrm{cm}^{2}$ (a typical value reflecting good electrical contacts and corresponding to that obtained experimentally - see the experimental part below), $T_{h}=305 \mathrm{~K}, T_{\infty}=300 \mathrm{~K}$ and $h_{e x}=400 \mathrm{~W} \mathrm{~m}^{-2} \mathrm{~K}^{-1}$, the search for the optimum values of the geometrical parameters $m$ and $l_{\text {gap }}$ (keeping $a, b$ and $e$ to the values given in Figure S3c) and of the electrical parameter $R_{\text {load }}$ within the parameter spaces $0.1 \mathrm{~mm}$ $\leq m \leq 0.8 \mathrm{~mm}, 0.1 \mathrm{~mm} \leq l_{\text {gap }} \leq 0.7 \mathrm{~mm}$ and free $R_{\text {load }}$ yielded $m=0.38 \mathrm{~mm}, l_{\text {gap }}=0.54$ $\mathrm{mm}$ and $R_{\text {load }}=73.5 \mathrm{~m} \Omega$, corresponding to a predicted $P_{\text {max }}$ of $5.5 \mu \mathrm{W}$ (Figure 9). Of note, in contrast to fixed boundary conditions for which $l_{\text {gap }}$ and $e$ are equivalent, these two geometrical parameters can be decoupled for mixed boundary conditions due to the fact that the thermal resistance of the TE part should be increased to optimize $P_{\text {max }}$. In this context, $l_{\text {gap }}$ offers an additional degree of freedom to increase the thermal resistance of the TE part. Nevertheless, the value of $l_{\text {gap }}$ should not be too high to ensure the good mechanical stability of the $\mu$-TEG, which justifies the above-mentioned limited range of values considered for this parameter. To verify these predictions experimentally, a $\mu$-TEG exhibiting this optimized geometry was fabricated and tested, as described in the next part. 


\section{Fabrication and testing of the $\mu$-TEGs}

\subsection{Fabrication of $\mu$-TEGs}

The starting point of the manufacturing process of the $\mu$-TEGs is a commercial flexible printed circuit board (PCB) made of co-laminated Kapton polyimide substrate with thick copper layer (Figure 10a). This basic component is bought as a long strip with drilled holes into which copper is deposited that play the role of the copper rivets (see Figure 1a), and with the wavyshaped paths patterned by a conventional photolithography technique. This last technique enables to easily vary the geometrical parameters of the wavy paths.

This strip is then processed on a pilot line following the sequence outlined in Figure 10b to 10f. For the entire production sequence, standard machines from electronics or surfacemounted-device (SMD) technology are used. A first deposition of a thin layer of an electroless nickel immersion gold (ENIG) layer is realized on the copper parts by a physical-vapordeposition (PVD) process (sputtering technology; Figure 10a). This layer helps to avoid oxidation, improve solderability of copper contacts and plays the role of a diffusion barrier between the copper layer and the thermoelectric materials. The $p$ - and $n$-doped $\mathrm{Bi}_{2} \mathrm{Te}_{3}$-based materials are applied on two distinct strips by magnetron sputtering to achieve a final thickness of $70 \mu \mathrm{m}$. Of note, to ease and lower the cost of the deposition step, the thermoelectric materials are deposited on the whole surface, that is, without a mask (Figure 10b). The chemical compositions of the $p$ - and $n$-type sputtering targets are ( $\left.\mathrm{Bi}_{0.25} \mathrm{Sb}_{0.75}\right)_{2} \mathrm{Te}_{3}$ and $\mathrm{Bi}_{2}\left(\mathrm{Te}_{0.9} \mathrm{Se}_{0.1}\right)_{3}$, respectively. To optimize the transport properties of the deposited $p$ - and $n$-type thermoelectric layers (see Table S1 in the ESI), a subsequent heat-treatment process at moderate temperatures (between 300 and $400^{\circ} \mathrm{C}$ ) is applied. Afterwards, the coated strips are mounted on UV-sensitive dicing tapes to be sawn into individual $p$ - and $n$-type elements (Figure 10c) and then assembled 
on PCBs with pick-and-place machines to form sub-systems soldered using a low-melting point solder (Figure 10d). These can be integrated in a customized quantity (Figure 10e) into products with interfaces to various heat sources and adapted heat sinks, offering many possible variations, such as the possibility of directly soldering the sub-systems, which places lower requirements on the planarity of the contacted surfaces. Another advantage of this simple process is the achievement of good electrical contact resistances, typically on the order of $10^{-5}$ $\Omega \mathrm{cm}^{2}$, that solely originate from the ENIG-thermoelectric materials interfaces.

Among the various geometries tested, we only consider hereafter that corresponding to the aforementioned optimum values determined using mixed boundary conditions. Of note, the presence of the ENIG diffusion barrier was not taken into account in the simulations due to its small thickness compared to that of the TE material (on the order of $200 \mathrm{~nm}$, that is, nearly two orders of magnitude lower) resulting in a negligible influence on the output performances (see Figure S9 in ESI) and significantly increasing the computational time. Moreover, we have further shown that the presence of TE material on the copper part does not affect the final results.

In order to increase the heat exchange capability of the $\mu$-TEG, an additional copper piece was soldered (see Figure 2) to drastically increase the total exchange surface area $S_{t}$ with respect to that of the thermocouple $S_{e x}$ yielding an equivalent $h_{e x}{ }^{e q}\left(h_{e x}^{e q}=h_{e x} S_{t} / S_{e x}\right)$ on the order of $400 \mathrm{~W} \mathrm{~m}^{-2} \mathrm{~K}^{-1}$, which corresponds to the upper limit of the $h_{e x}$ values used in our simulations. The final $\mu$-TEG consists in a bar composed of 15 thermocouples connected electrically in series (see Figure 11a). A heater was brazed onto one side of the copper parts to fix its temperature to $T_{h}=305 \mathrm{~K}$.

To demonstrate the versatility of this technology, another $\mu$-TEG composed of eight bars (Figure 11b), that is 120 thermocouples, was also fabricated and characterized in the heat sink limited mode for which, $T_{\infty}=300 \mathrm{~K}$ and $T_{h}$ was varied from 305 up to $405 \mathrm{~K}$, which is the 
maximum temperature compatible with this technology. Increasing $T_{h}$ above $305 \mathrm{~K}$ requires to increase the exchange surface area at the cold side. To fulfill this requirement, a heat sink, with a thermal resistance of $1.45 \mathrm{~K} \mathrm{~W}^{-1}$, corresponding to $h_{e x}{ }^{e q} \approx 33000 \mathrm{~W} \mathrm{~m}^{-2} \mathrm{~K}^{-1}$, was soldered on one side of the copper parts (Figure 11b). A heater was brazed on the other side to monitor the temperature increase up to $405 \mathrm{~K}$.

In both cases, the measured output voltage values of the harvester and the voltage at a shunt resistor for current determination were recorded. To acquire current-voltage characteristics, temperature equilibrium was waited for at each measured temperature. From these data, the maximum output power $P_{\max }$ was inferred and compared to that predicted by our model.

\subsection{Measurement results and comparison with theoretical predictions}

For both devices, we considered as a first approximation that the transport properties of the materials are temperature independent. The hot temperature $T_{h}$ was either considered as fixed $\left(T_{h}=305\right.$ for the first device) or varied between 305 and $405 \mathrm{~K}$ (second device) with $T_{\infty}$ $=300 \mathrm{~K}$ and an electrical contact resistance fixed to $\rho_{c}=10^{-5} \Omega \mathrm{cm}^{2}$. Solving numerically this problem for one thermocouple, the output power of the 15 (120) thermocouples forming the first (second) device can be then obtained.

The predicted values for $P_{\max }(=82.5 \mu \mathrm{W})$ and the output voltage $(=3.9 \mathrm{mV})$ for the first $\mu$-TEG are in excellent agreement with the experimental values $\left(P_{\max }=80.9 \mu \mathrm{W}\right.$ and output voltage $=3.9 \mathrm{mV}$ ). For a meaningful comparison of these performances with those of the literature, the output power was normalized to the area $A_{d}$ of the device and to the temperature difference applied on the device squared $(\Delta T)^{2}$ (see Table S1 in the ESI). This coefficient, referred to as the specific power generation capacity or the TE efficiency factor, ${ }^{27,29}$ is an 
extrinsic device metric that depends on the operating mode. More commonly, the operating mode consists in connecting a heater and an "infinite" heat sink to the device, a situation approaching fixed temperature boundary conditions. The second mode, using a heater and a limited heat sink (mixed boundary conditions), has been only scarcely considered in the literature due to the lower output power values and hence, the lower efficiency factors, measured in this mode. Taking $\Delta T=5 \mathrm{~K}$ and considering that $A_{d}=40.75 \mathrm{~mm}^{2}$, the values of the efficiency factor are $38 \mu \mathrm{W} \mathrm{cm}-2 \mathrm{~K}^{-2}$ and $7.9 \mu \mathrm{W} \mathrm{cm}{ }^{-2} \mathrm{~K}^{-2}$, in the first and second mode, respectively. These values, compared to those delivered by other devices based on in-plane or cross-plane technology in the first mode are reported as a function of the filling fraction (defined as the ratio of the total area of thermocouples perpendicular to the heat flow to $A_{d}$ ) in Figure 1b. This comparison demonstrates that the performances of our $\mu$-TEG stand at an excellent level. In the first mode, our result is the best among in-plane designs and approaches those of the best cross-plane $\mu$-TEGs while, in the second mode, our result surpasses the record-value of $1.9 \mu \mathrm{W} \mathrm{cm}{ }^{-2} \mathrm{~K}^{-2}$ obtained by Böttner et al. ${ }^{34}$ Furthermore, our $\mu$-TEG outperforms prior results obtained for similar filling rates by two to three orders of magnitude, indicating that even higher performances may be achieved by further downsizing the thermocouples. The comparison with prior results further highlights that $\mathrm{Bi}_{2} \mathrm{Te}_{3}$-based compounds remain the materials of choice for the design of efficient $\mu$-TEGs near room temperature, despite the advantages offered by the well-mastered processing technologies of silicon and the recent advances achieved. ${ }^{29}$

The predictions for the second $\mu$-TEG composed of 120 thermocouples, presented in Figure 12, also evidence an excellent match with the experimental values, the deviations being at most $15 \%$ for the output power and $4 \%$ for the output voltage. As expected, both quantities increase with increasing $\Delta T=T_{h}-T_{\infty}$. At the maximum $\Delta T$, output power and output voltage of up to $0.1 \mathrm{~W}$ and $0.5 \mathrm{~V}$, respectively, can be obtained, showing the high level of performance 
of our device. Of note, except for $\Delta T=5 \mathrm{~K}$, the output powers of this $\mu$-TEG are not the optimum values, making the optimization of the design of the $\mu$-TEG specific to a given $\Delta T$. Higher performances may be anticipated by increasing the filling rate of our $\mu$-TEG, potentially breaking the record values reported so far, regardless of the technology considered.

\section{Conclusions}

We reported on a novel architecture of a flexible $\mu$-TEG exhibiting an overall vertical, in-plane configuration, which consists in wavy-shaped $\mathrm{Bi}_{2} \mathrm{Te}_{3}$-based TE materials deposited on laminated copper/polyimide/copper plates, with the copper plates favoring the heat transfer to the heat source and sink. In comparison to previously proposed architectures, this design offers several advantages that include i) a larger flexibility due to the small thickness of the copper plates and polyimide substrate, ii) a low electrical resistance thanks to a large surface and comparatively high thickness of the TE materials, iii) a high thermal resistance (typically around $1 \mathrm{~K} \mathrm{~W}^{-1}$ for $1 \mathrm{~cm}^{2}$ area of TE elements) due to the specific geometry used, iv) the possibility to adapt the electrical and thermal resistances to specific applications by varying the geometry of the $n$ - and $p$-type legs, v) the use of copper plates that can both play the role of heat spreaders and be easily soldered to the heat source and/or to a heat sink for dissipation when required, vi) a simple, easily-scalable fabrication process leading to a flexible, yet mechanically-robust structure. In excellent agreement with numerical models based on finiteelement analyses, we demonstrate that high thermoelectric performances can be achieved near room temperature, with a high electrical power generation of $5.5 \mu \mathrm{W}$ per thermocouple when operating under a temperature difference of only $5 \mathrm{~K}$. The performances of two $\mu$-TEG devices composed of 15 and 120 thermocouples with optimized geometries, fabricated using an easilyscalable process based on current SMD technology, closely follow the predictions of finite- 
element analyses, evidencing the excellent control of the electrical contact resistances achieved experimentally. These results, that rank these $\mu$-TEGs among the best devices developed to date, demonstrate that this architecture is promising for developing TE devices for power generation applications operating around room temperature. Thanks to its versatile design and strong integration capacity for energy harvesting, the delivered output power can span the range from $\mu \mathrm{W}$ to $\mathrm{mW}$, a useful range for a plethora of applications. In this regard, the effectiveness of our design is demonstrated by two applications where these $\mu$-TEGs are currently tested, that is, for gas pipe monitoring and bearing condition monitoring on trains. ${ }^{53}$

\section{Author contributions}

B. L., F. K., A. D. and C. C. designed and supervised the theoretical part of the project. S. O. conducted the simulations of the devices. S. O., F. K. and B. L. analyzed the results. G. S., E. M. and J. P. fabricated and tested the device. C. C. and B. L. wrote the manuscript with inputs from all other authors.

\section{Conflicts of interest}

The authors declare no conflicts of interest.

\section{Acknowledgements}

The authors acknowledge the financial support of the European project ENSO ("Energy for Smart Objects"; http://enso-ecsel.eu). This project has received funding within the Electronic Components and Systems for European Leadership Joint Undertaking (ECSEL JU) program under grant agreement $\mathrm{n}^{\circ}$ 692482. This JU receives support from the European Union's H2020 research and innovation program and France, Netherlands, Denmark, Belgium, Germany, Czech Republic and Spain. 


\section{Tables}

Table 1. Comparison of the optimum values of $m$ and $\Delta T$ obtained by an analytical and numerical (with Comsol Multiphysics) approach for $T_{h}=305 \mathrm{~K}$ and $T_{\infty}=300 \mathrm{~K}$. The relative errors are given in parenthesis.

\begin{tabular}{|c|c|c|c|c|}
\hline $\boldsymbol{h}_{\text {ex }}\left(\mathrm{W} \mathrm{m}^{-2} \mathrm{~K}^{-1}\right)$ & $\begin{array}{c}\boldsymbol{m}_{\text {optimum }}(\text { Comsol) } \\
(\mathrm{mm})\end{array}$ & $\begin{array}{c}\boldsymbol{m}_{\text {optimum }}(\text { analytic }) \\
(\mathbf{m m})\end{array}$ & $\begin{array}{c}\Delta T_{\text {optimal }} \text { (Comsol) } \\
(\mathrm{K})\end{array}$ & $\begin{array}{c}\Delta T_{\text {optimal }} \text { (analytic) } \\
(\mathrm{K})\end{array}$ \\
\hline 40 & - & 2.61 & - & 2.50 \\
\hline 200 & $0.65(16 \%)$ & 0.56 & $2.42(3 \%)$ & 2.50 \\
\hline 400 & $0.37(6 \%)$ & 0.35 & $2.55(2 \%)$ & 2.50 \\
\hline
\end{tabular}




\section{References}

1 S. Bauer, Nat. Mater., 2013, 12, 871-872.

2 J. P. Heremans, M. S. Dresselhaus, L. E. Bell and D. T. Morelli, Nat. Nanotechnol., 2013, 8, $471-473$.

3 Q. Xu, S. Qu, C. Ming, P. Qiu, Q. Yao, C. Zhu, T.-R. Wei, J. He, X. Shi and L. Chen, Energy Environ. Sci., 2020, 13, 511-518.

4 Y. Qi and M. C. McAlpine, Energy Environ. Sci., 2010, 3, 1275-1285.

5 M. He, J. Ge, Z. Lin, X. Feng, X. Wang, H. Lu, Y. Yang and F. Qiu, Energy Environ. Sci., $2012,5,8351-8358$.

6 C. Wan, X. Gu, F. Dang, T. Itoh, Y. Wang, H. Sasaki, M. Kondo, K. Koga, K. Yabuki, G. J. Snyder, R. Yang and K. Koumoto, Nat. Mater., 2015, 14, 622-627.

7 Y. Lu, Y. Qiu, K. Cai, Y. Ding, M. Wang, C. Jiang, Q. Yao, C. Huang, L. Chen and J. He, Energy Environ. Sci., 2020, 13, 1240-1249.

8 C. Bounioux, P. DıÅLaz-Chao, M. Campoy-Quiles, M. S. Martin-Gonzalez, A. R. Goni, R. Yerushalmi-Rozen and C. Müller, Energy Environ. Sci., 2013, 6, 918-925.

9 X. Hu, P. Jood, M. Ohta, M. Kunii, K. Nagase, H. Nishiate, M. G. Kanatzidis and A. Yamamoto, Energy Environ. Sci., 2016, 9, 517-529.

10 S. J. Kim, J. H. We, B. J. Cho, Energy Environ. Sci., 2014, 7, 1959-1965.

11 P. Kumar, E.W. Zaia, E. Yildirim, D. V. M. Repaka, S.-W. Yang, J. J. Urban and K. Hippalgaonkar, Nat. Commun., 2018, 9, 5347.

12 D. Kraemer, Q. Jie, K. McEnaney, F. Cao, W. Liu, L. A. Weinstein, J. Loomis, Z. Ren and G. Chen, Nat. Energy, 2016, 1, 16153.

13 C. Yang, D. Souchay, M. Kneiß, M. Bogner, H. M. Wei, M. Lorenz, O. Oeckler, G. Benstetter, Y. Q. Fu and M. Grundmann, Nat. Commun., 2017, 8, 16076. 
14 J. Peng, I. Witting, N. Geisendorfer, M. Wang, M. Chang, A. Jakus, C. Kenel, X. Yan, R. Shah, G. J. Snyder and M. Grayson, Nat. Commun., 2019, 10, 2619.

15 D. M. Rowe, in Thermoelectrics and its Energy Harvesting: Modules, Systems, and Applications in Thermoelectrics, ed. D. M. Rowe, CRC Press, Boca Raton, 2012.

16 X.-L. Shi, J. Zou, Z.-G. Chen, Chem. Rev. https://doi.org/10.1021/acs.chemrev.0c00026.

17 Q. H. Zhang, X. Y. Huang, S. Q. Bai, X. Shi, C. Uher, L. D. Chen, Adv. Eng. Mater., 2016, 18, 194-213.

18 N. Jaziri, A. Boughamoura, J. Müller, B. Mezghani, F. Tounsi, M. Ismail, Energy Rep. https://doi.org/10.1016/j.egyr.2019.12.011.

19 M. Stordeur and I. Stark, Proceedings ICT'97. 16th International Conference on Thermoelectrics, p. 575-577, 1997.

20 H. Bottner, J. Nurnus, A. Gavrikov, G. Kuhner, M. Jagle, C. Kunzel, D. Eberhard, G. Plescher, A. Schubert, K.-H. Schlereth, J. Microelectromechanical Syst., 2004, 13, 414-420.

21 J. Weber, K. Potje-Kamloth, F. Haase, P. Detemple, F. Voelklein and T. Doll, Sens. Actuators Phys., 2006, 132, 325-330.

22 S. J. Kim, J. H. We and B. J. Cho, Energy Environ. Sci., 2014, 7, 1959-1965.

23 T. Varghese, C. Hollar, J. Richardson, N. Kempf, C. Han, P. Gamarachchi, D. Estrada, R. J. Mehta and Y. Zhang, Sci. Rep., 2016, 6, 33135.

24 F. Kim, B. Kwon, Y. Eom, J. E. Lee, S. Park, S. Jo, S. H. Park, B.-S. Kim, H. J. Im, M. H. Lee, T. S. Min, K. T. Kim, H. G. Chae, W. P. King and J. S. Son, Nature Ener., 2018, 3, 301309.

25 G. J. Snyder, J. R. Lim, C.-K. Huang and J.-P. Fleurial, Nat. Mater., 2003, 2, 528-531. 26 W. Glatz, S. Muntwyler and C. Hierold, Sens. Actuators Phys., 2006, 132, 337-345.

27 W. Glatz, E. Schwyter, L. Durrer, C. Hierold, J. Micromech. Systems, 2009, 18, 763-772. 28 Z. Zhang, J. Qiu, S. Wang, Manufacturing Letters, 2016, 8, 6-10. 
29 G. Hu, H. Edwards, and M. Lee, Nat. Electron., 2019, 2, 300-306.

30 M. Strasser, R. Aigner, C. Lauterbach, T.F. Sturm, M. Franosch, and G. Wachutka, Sens. Actuators A, 2004, 114, 362-370.

31 Z. Wang, V. Leonov, P. Fiorini, and C. Van Hoof, Sens. Actuators Phys., 2009, 156, 95102.

32 D. M. Rowe, D. V. Morgan, and J. H. Kiely, Electron. Lett., 1989, 25, 166-168.

33 H. Glosch, M. Ashauer, U. Pfeiffer, and W. Lang, Sens. Actuators Phys., 1999, 74, 246250.

34 H. Bottner, J. Nurnus, A. Schubert, and F. Volkert, $26^{\text {th }}$ International Conference on Thermoelectrics, p. 306-309 (2007).

35 G. J. Snyder, J. R. Lim, C.-K. Huang, and J.-P. Fleurial, Nat. Mater., 2004, 2, 528-531.

36 M. Takashiri, T. Shirakawa, K. Miyazaki, and H. Tsukamoto, Sens. Actuators Phys., 2007, 138, 329-334.

37 Ii-Ho Kim and Dong-Hi Lee, in $15^{\text {th }}$ International Conference on Thermoelectrics. Proceedings ICT '96, p. 425-429 (1996).

38 M. Kishi, Y. Yoshida, H. Okano, H. Nemoto, Y. Funanami, M. Yamamoto and H. Kanazawa, Proceedings ICT'97. 16th International Conference on Thermoelectrics, p. 653656, 1997.

39 R. Roth, R. Rostek, K. Cobry, C. Köhler, M. Groh and P. Woias, J. Microelectromechanical Syst., 2014, 23, 961-971.

40 W. Zhang, J. Yang and D. Xu, J. Microelectromechanical Syst., 2016, 25, 744-749.

41 A. Chen, D. Madan, P. K. Wright, and J. W. Evans, J. Micromechanics Microengineering, 2011, 21, 104006. 
42 L. Francioso, C. De Pascali, P. Siciliano, A. De Risi, S. D’Amico, C. Veri and M. Pasca, 5th IEEE International Workshop on Advances in Sensors and Interfaces IWASI, p. 104 - 107, 2013.

43 K. Pudzs, A. Vembris, M. Rutkis, and S. Woodward, Adv. Electron. Mater., 2017, 3, 1600429.

44 T. Sun, B. Zhou, Q. Zheng, L. Wang, W. Jiang, and G. J. Snyder, Nat. Commun., 2020, 11, 572.

45 W. Zhou, Q. Fan, Q. Zhang, L. Cai, K. Li, X. Gu, F. Yang, N. Zhang, Y. Wang, H. Liu, W. Zhou and S. Xie, Nat. Commun., 2017, 8, 1-9.

46 K. Itoigawa, H. Ueno, M. Shiozaki, T. Toriyama and S. Sugiyama, J. Micromechanics Microengineering, 2005, 15, S233 - S238.

47 E. Mu, G. Yang, X. Fu, F. Wang, Z. Hu, J. Pow. Sour., 2018, 394, 17-25.

48 Y. Liu, E. Mu, Z. Wu, Z. Che, F. Sun, X. Fu, F. Wang, X. Wang, Z. Hu, Nano Converg., 2020, 7, 8 .

49 R. He, G. Schierning and K. Nielsch, Adv. Mater. Technol., 2018, 3, 1700256.

50 J. Yan, X. Liao, D. Yan and Y. Chen, J. Microelectromechanical Syst., 2018, 27, 1-18.

51 I. Stark in Micro Energy Harvesting, Eds D. Briand, E. Yeatman and S. Roundy, Wiley, p. 245-269 (2015).

52 J.-H. Bahk, H. Fang, K. Yazawa and A. Shakouri, J. Mater. Chem. C, 2015, 3, 10362-10374. 53 see http://enso-ecsel.eu.

54 R. R. Heikes and R. W. Ure in Thermoelectricity: Science and Engineering, Interscience Publishers, New-York - London, 1961.

55 Advanced thermoelectrics: materials, contacts, devices, and systems, Eds Z. Ren, Y. Lan and Q. Zhang, CRC Press, 2017.

56 P.M. Mayer and T.J. Ram, Nanosc. Microsc.Therm., 2006, 10, 143-155. 
57 Y. Apertet, H. Ouerdane, O. Glavatskaya, C. Goupil and P. Lecoeur, EPL, 2012, 97, 28001.

\section{Figure Captions}

Fig. 1 (a) Perspective view of the design of our planar $\mu$-TEG. The $n$ - and $p$-type $\mathrm{Bi}_{2} \mathrm{Te}_{3}$-based materials form a wavy-shaped path, deposited on the polyimide, itself on the $\mathrm{Cu}$ plates, separated by a gap. The polyimide layer is sandwiched by the two $\mathrm{Cu}$ plates. Both $\mathrm{Cu}$ plates are connected by $\mathrm{Cu}$ rivets that ensure a good thermal contacts between them. (b) Maximum output power densities as a function of the filling rate, defined as the ratio of the total area of the TE materials by the total area of the device, for various in-plane and cross-plane $\mu$-TEGs. For comparison purposes, all the densities are given for a temperature difference $\Delta T$ of $5 \mathrm{~K}$. The high power density achieved by our $\mu$-TEG ranks this system among the best micro-devices currently available. ${ }^{19,27,29-46} \mathrm{~A}$ complete description of all the $\mu$-TEGs mentioned in panel (b) is available in Table $\mathrm{S} 1$ in the ESI.

Fig. 2 a) Schematic view of the $\mu$-TEG showing the main geometric parameters used for the parameterization of the structure in Comsol Multiphysics. The lower panel corresponds to a projection of the structure shown in the upper panel. b) Thermocouple soldered to two heat sinks. c) The TE module can be obtained by assembling these basic units, each of them being connected to two heat sinks.

Fig. 3 Temperature (left structures) and electrical potential (right structures) profiles calculated under open circuit conditions for temperature differences $\Delta T$ of 1 (upper), 5 (middle) and $10 \mathrm{~K}$ (lower). 
Fig. 4 (left panels ) Output power of the thermocouple as a function of the parameter $s=$ $R_{\text {load }} / R$ for temperature differences $\Delta T$ of 1 (upper), 5 (middle) and $10 \mathrm{~K}$ (lower). (right panels) Corresponding characteristic curves $U(I)$.

Fig. 5 Maximum output power $P_{\max }$ as a function of the load resistance $R_{\text {load }}$ calculated for a temperature difference $\Delta T$ of $1 \mathrm{~K}$ for various values of the electrical contact resistance $\rho_{c}$.

Fig. 6 Maximum output power $P_{\max }$ as a function of $m$ for a fixed hot side temperature $T_{h}=$ $305 \mathrm{~K}, T_{\infty}=300 \mathrm{~K}$ and for various values of the heat transfer coefficient $h_{\text {ex }}$.

Fig. 7 Output power of the thermocouple as a function of the parameter $s=R_{\text {load }} / R$ calculated for various values of the heat transfer coefficient $h_{e x}$ and for temperatures at the hot side of a) $T_{h}=305 \mathrm{~K}$ and $T_{\infty}=300 \mathrm{~K}$ and b) $T_{h}=310 \mathrm{~K}$ and $T_{\infty}=300 \mathrm{~K}$.

Fig. 8 Maximum output power $P_{\max }$ as a function of the length of the TE materials calculated for various values of the electrical contact resistance $R_{c}$ with $T_{h}=305 \mathrm{~K}, T_{\infty}=300 \mathrm{~K}$ and a heat transfer coefficient $h_{e x}$ of $400 \mathrm{~W} \mathrm{~m}^{-2} \mathrm{~K}^{-1}$.

Fig. $93 \mathrm{D}$ plot showing the evolution of the maximum output power $P_{\max }$ as a function of the gap between the two upper $\mathrm{Cu}$ plates $l_{\text {gap }}$ and the length of the TE materials $m$ for an external load resistance $R_{\text {load }}$ of $73.5 \mathrm{~m} \Omega$.

Fig. 10 Fabrication process of the $\mu$-TEG. The commercial, flexible PCBs (panel a) are composed of copper-polyimide co-laminated with drilled holes and patterned wavy-shaped paths, onto which a very thin ENIG (electroless nickel immersion gold) layer is deposited by 
PVD. The $n$ - and $p$-type thermoelectric materials are deposited by magnetron sputtering yielding $n$ - and $p$-type strips (panel b). After an annealing step, the long strips are diced into individual $n$ - and $p$-type elements (panel c), which are then soldered alternatively onto copper parts (panel d). Several of these units, composed of several pairs of $n$ - and $p$-type elements, are then assembled (panel e) before being contacted to a heat exchanger (panel f).

Fig. 11 a) Schematic view of a unit consisting of 15 thermocouples, connected electrically in series. Each basic unit is connected to two heat sinks made of copper. The wavy-shaped $p$ - and n-type thermoelectric materials are highlighted in green and red, respectively. b) Example of an assembly of several units shown in a). c) Fabricated $\mu$-TEG with the heat exchanger shown in black, and the thermoelectric elements protected by the blue housing.

Fig. 12 Comparison of the experimental values of the a) maximum output power $P_{\max }$ and b) voltage at $P_{\max }$ with those obtained by the numerical simulations for various temperature differences $\Delta T=T_{h}-T_{\infty}$. 
a)

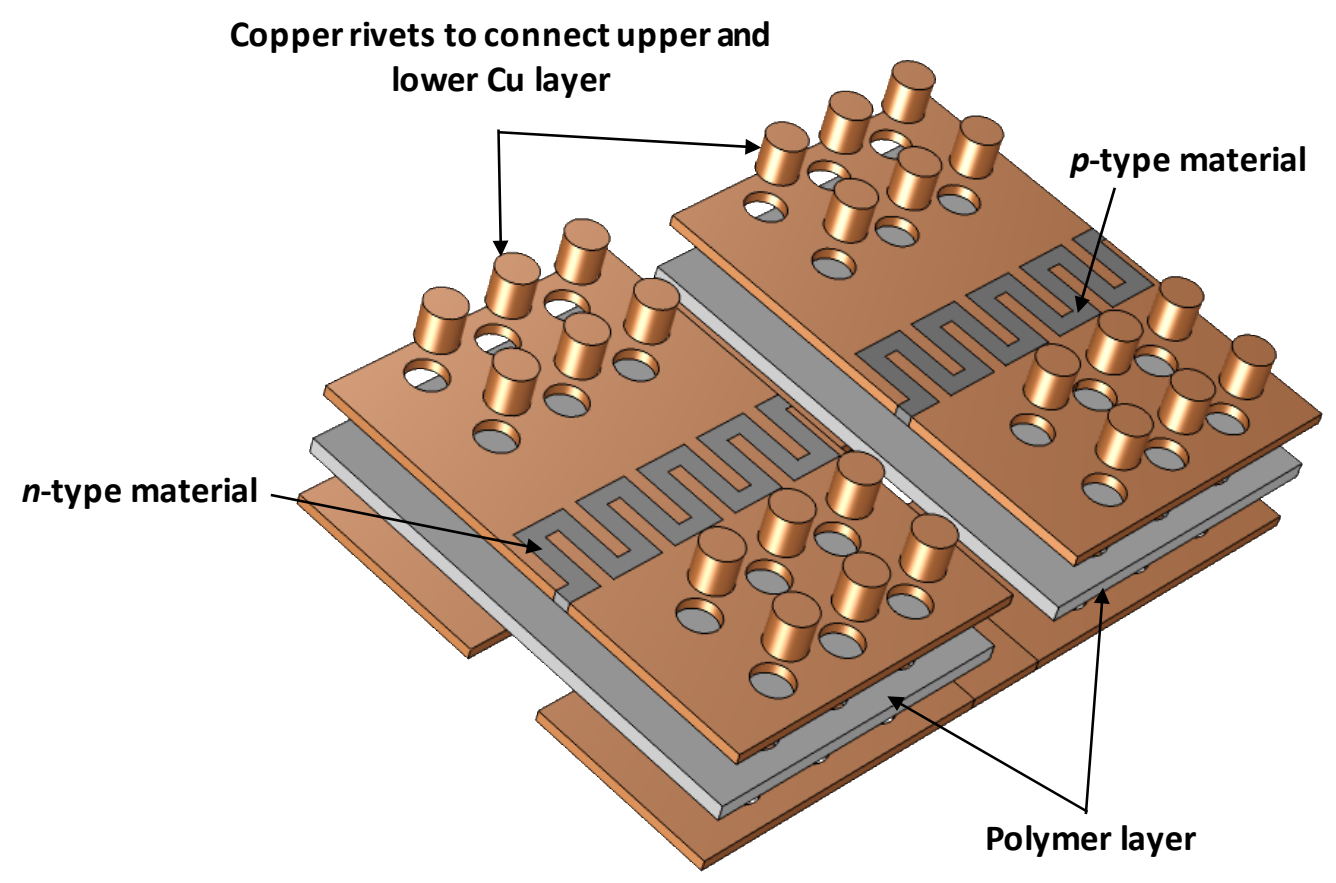

b)

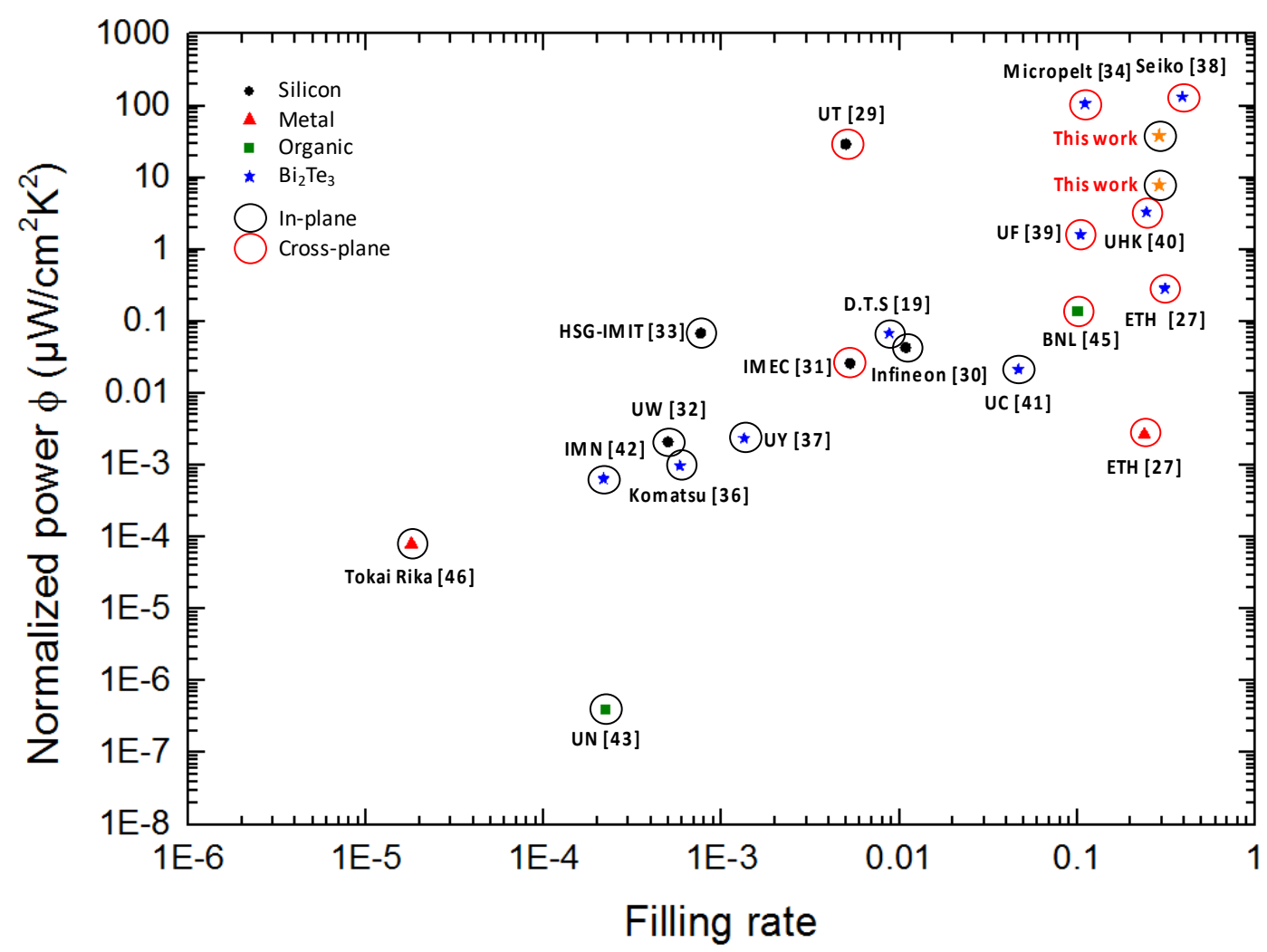

Figure 1 
a)

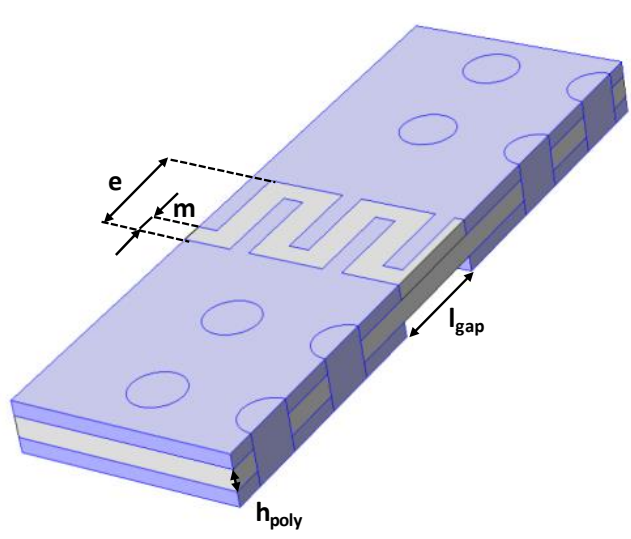

Copper rivet

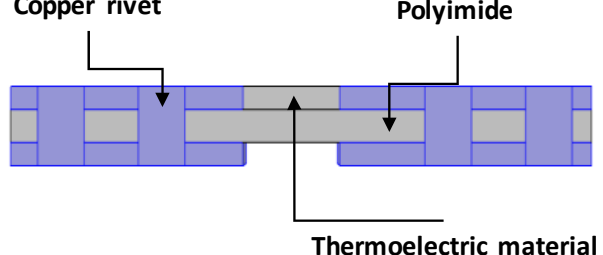

c)

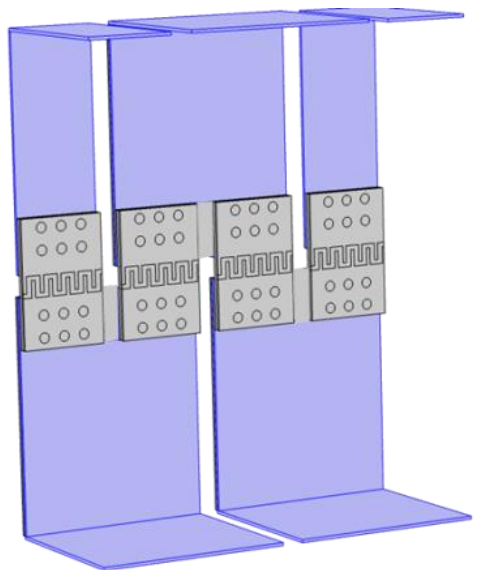

b)

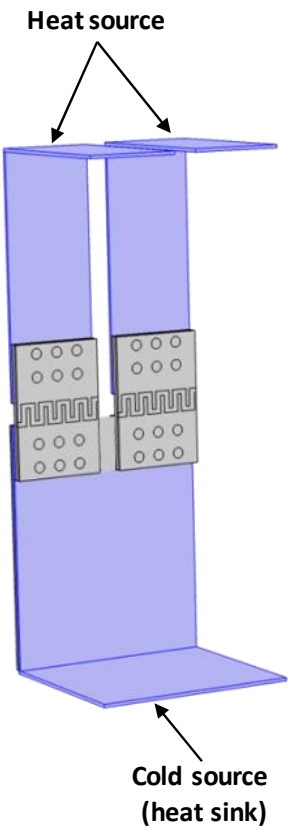

Figure 2 

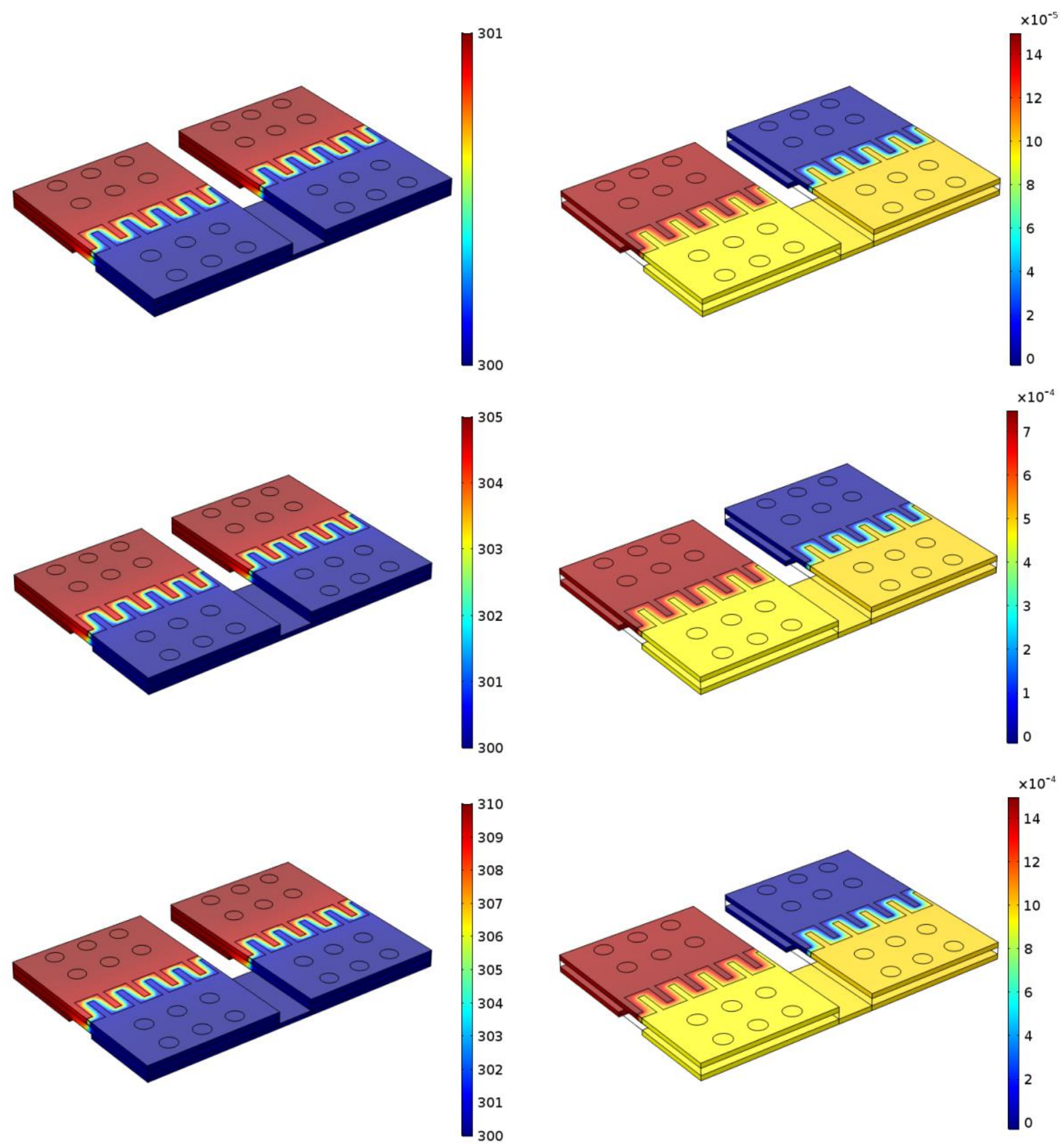

Figure 3 

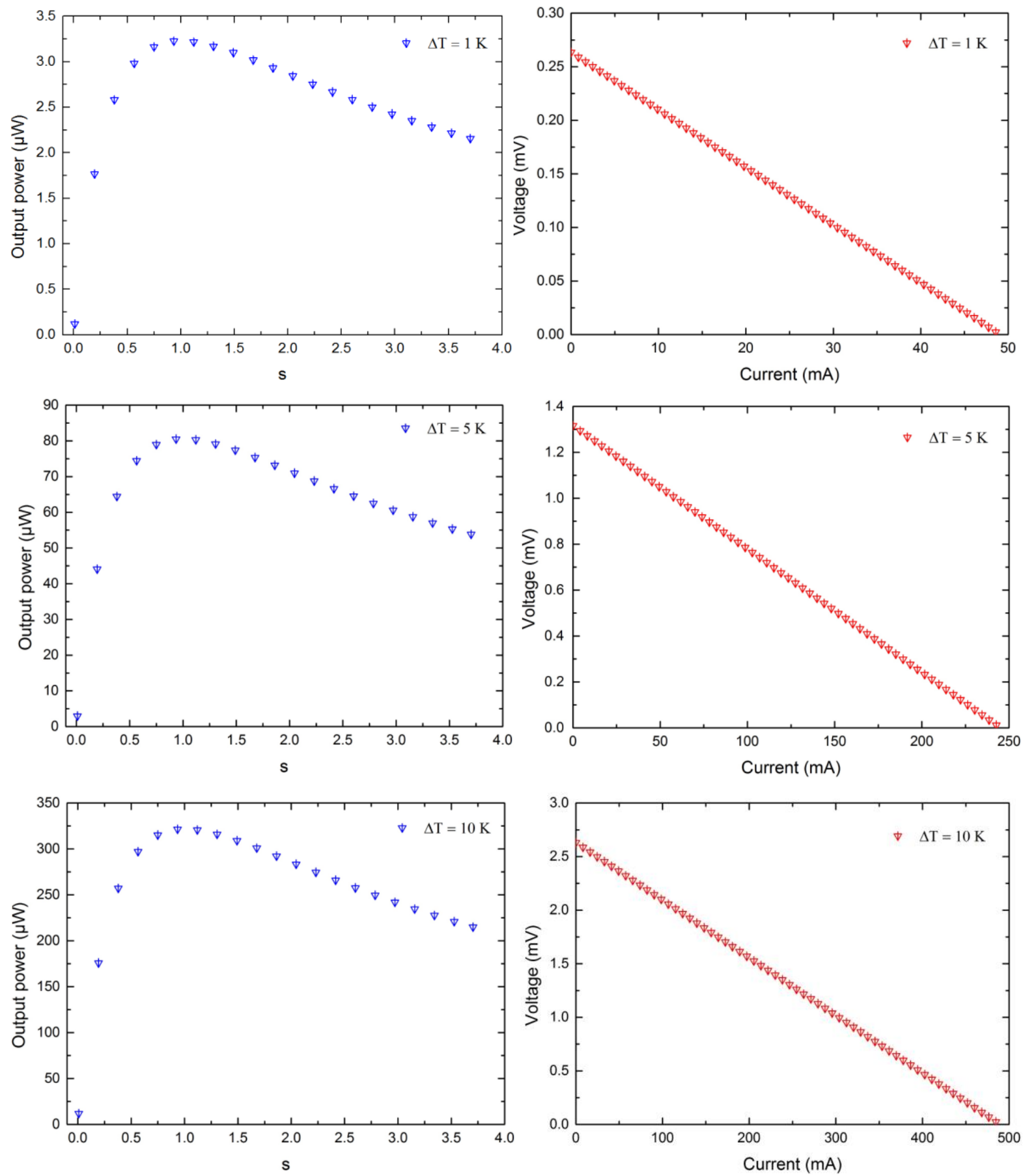

Figure 4 


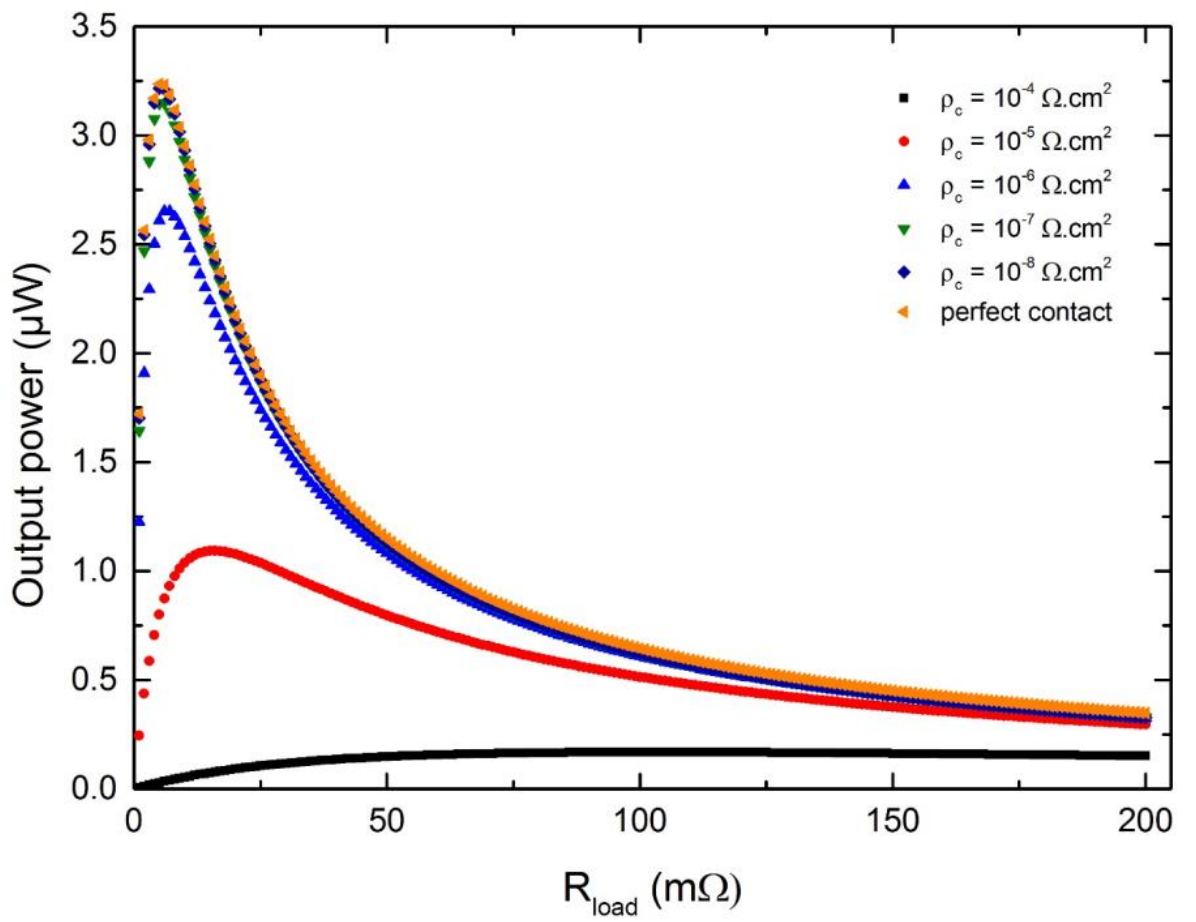

Figure 5 


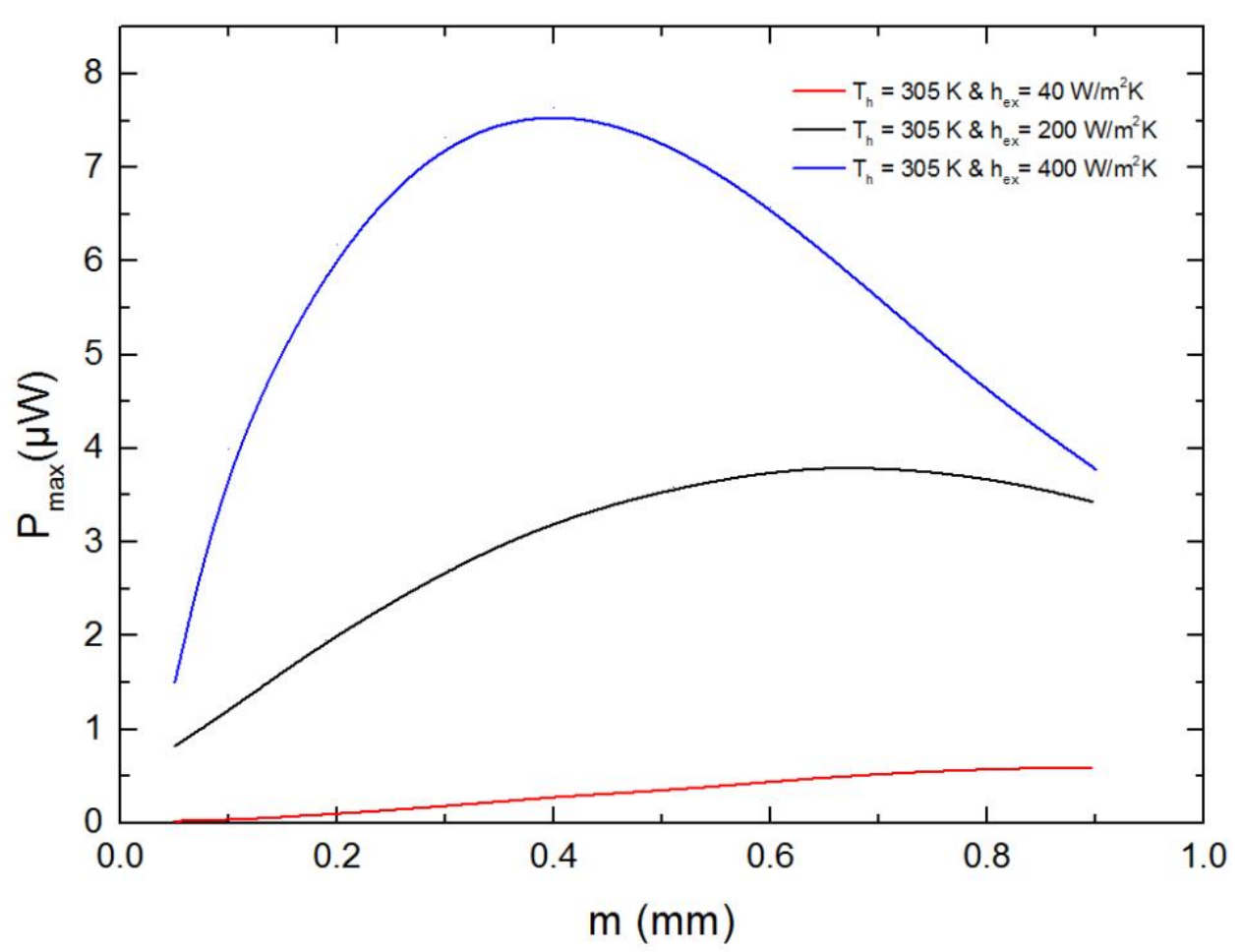

Figure 6 
a)

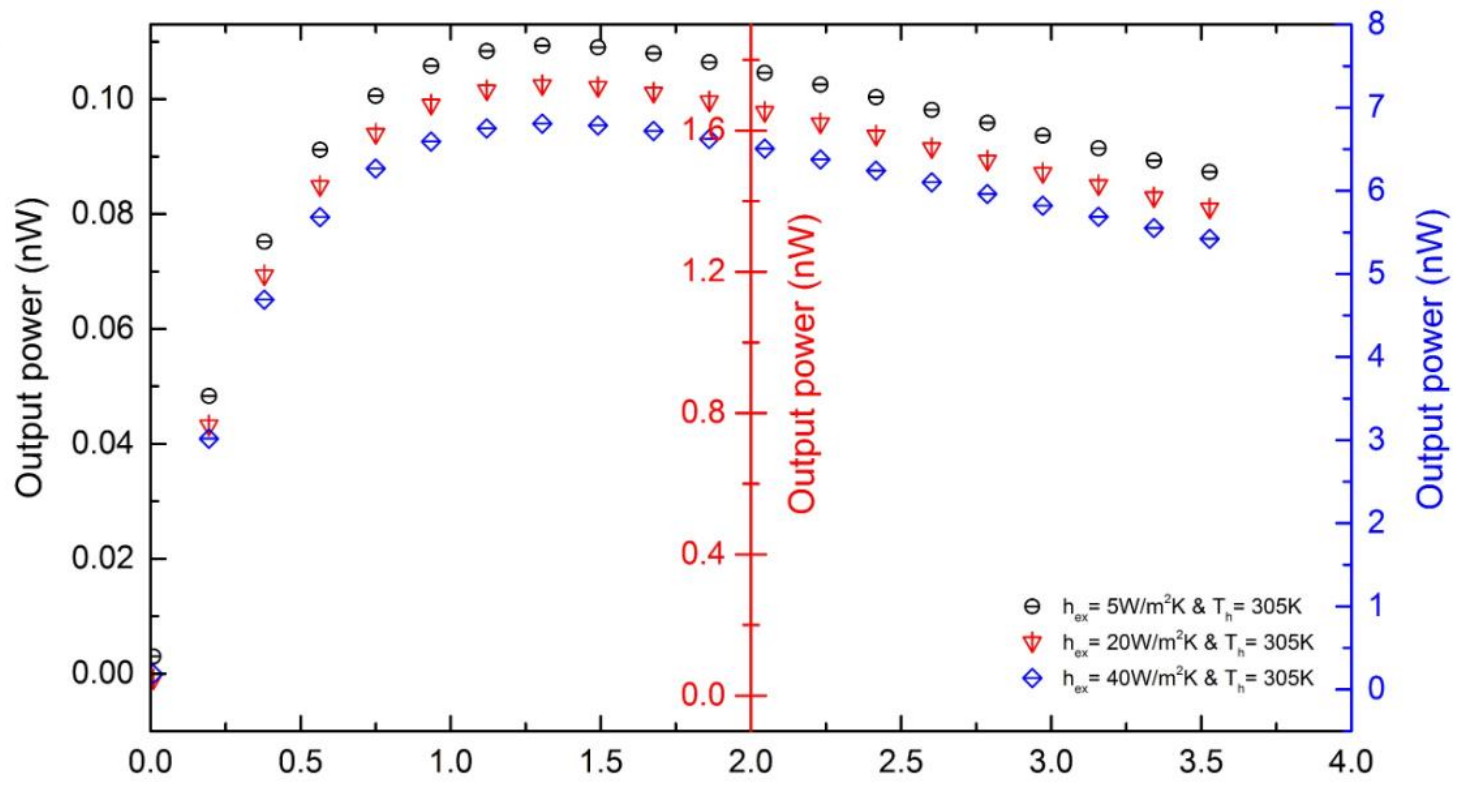

b)

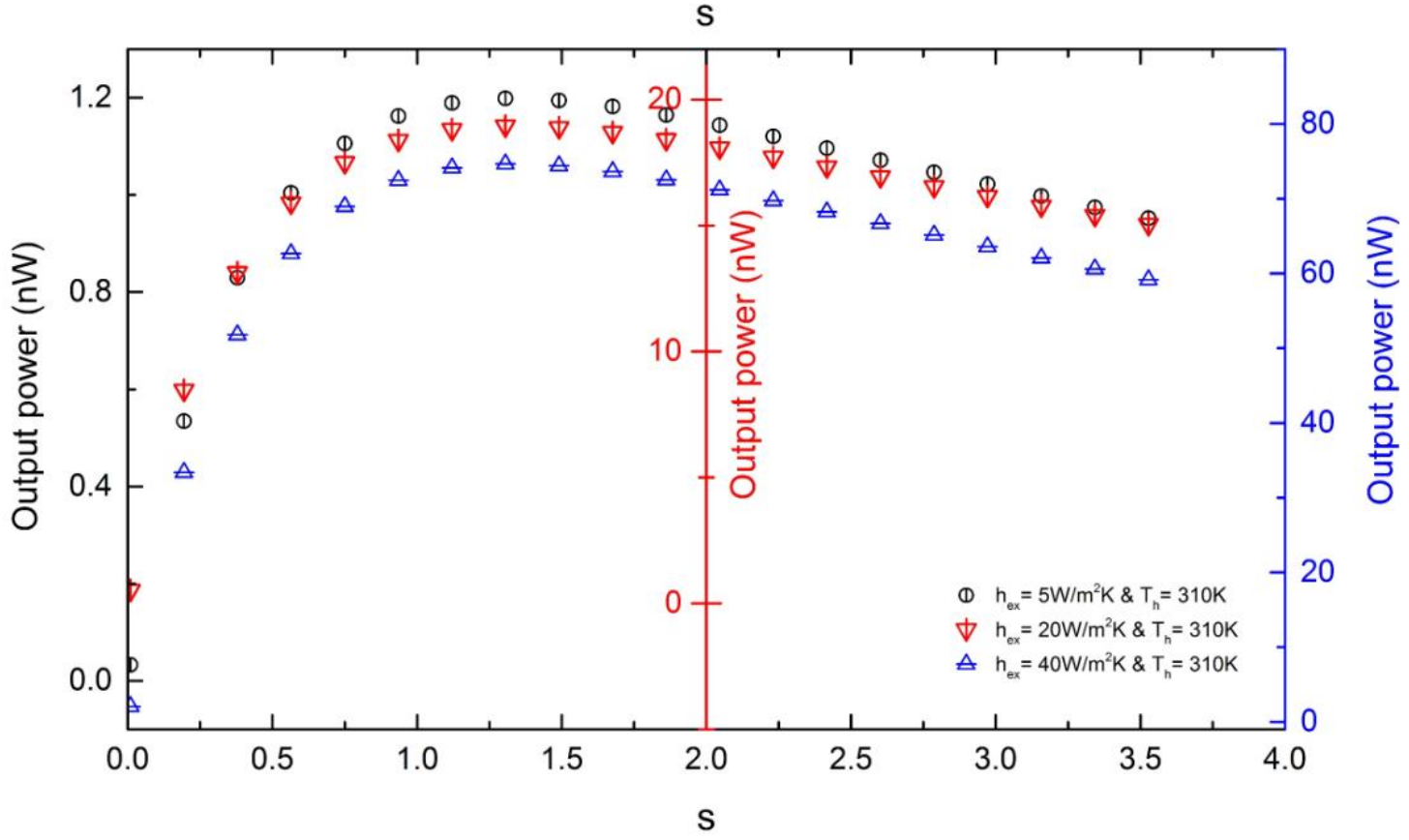

Figure 7 


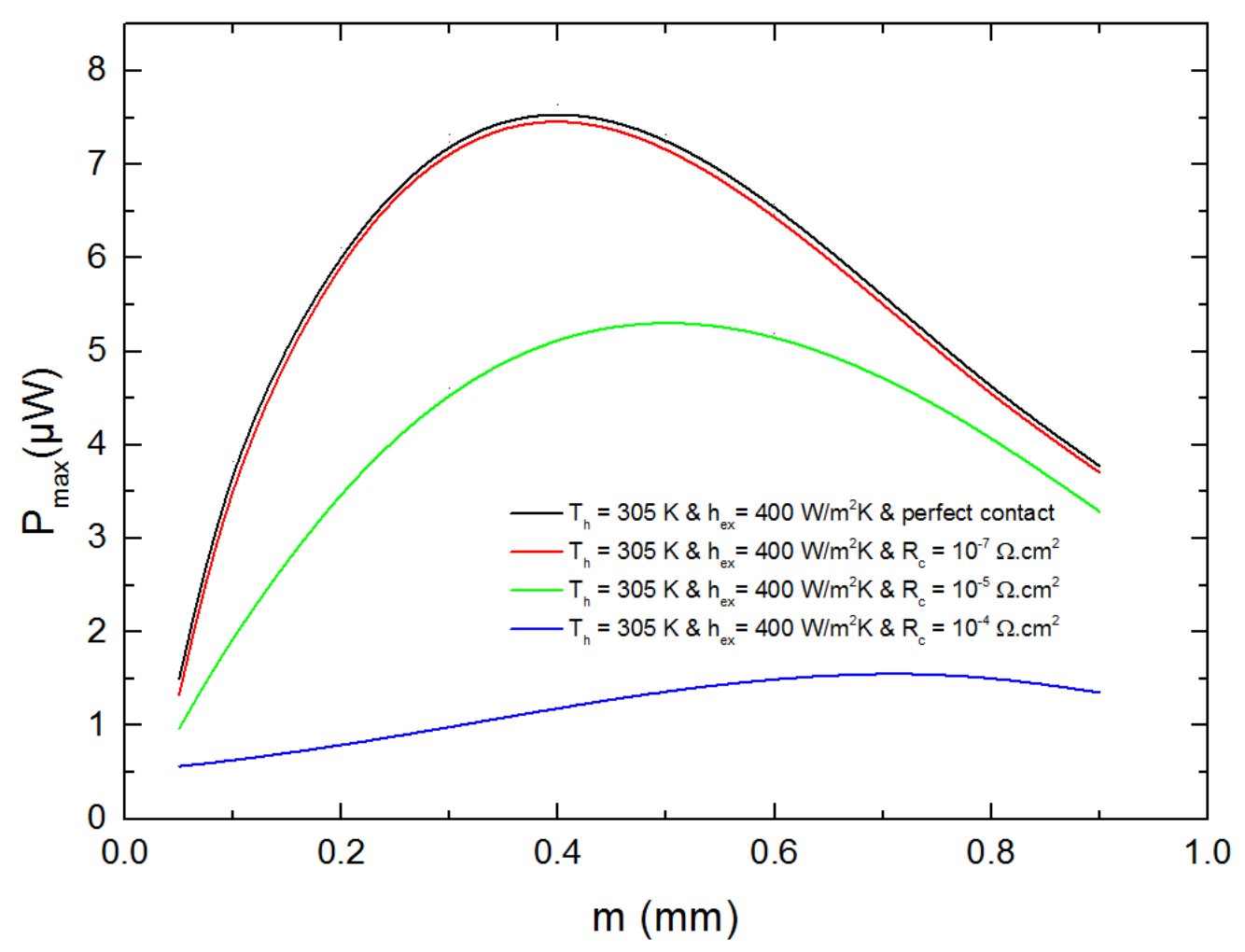

Figure 8 


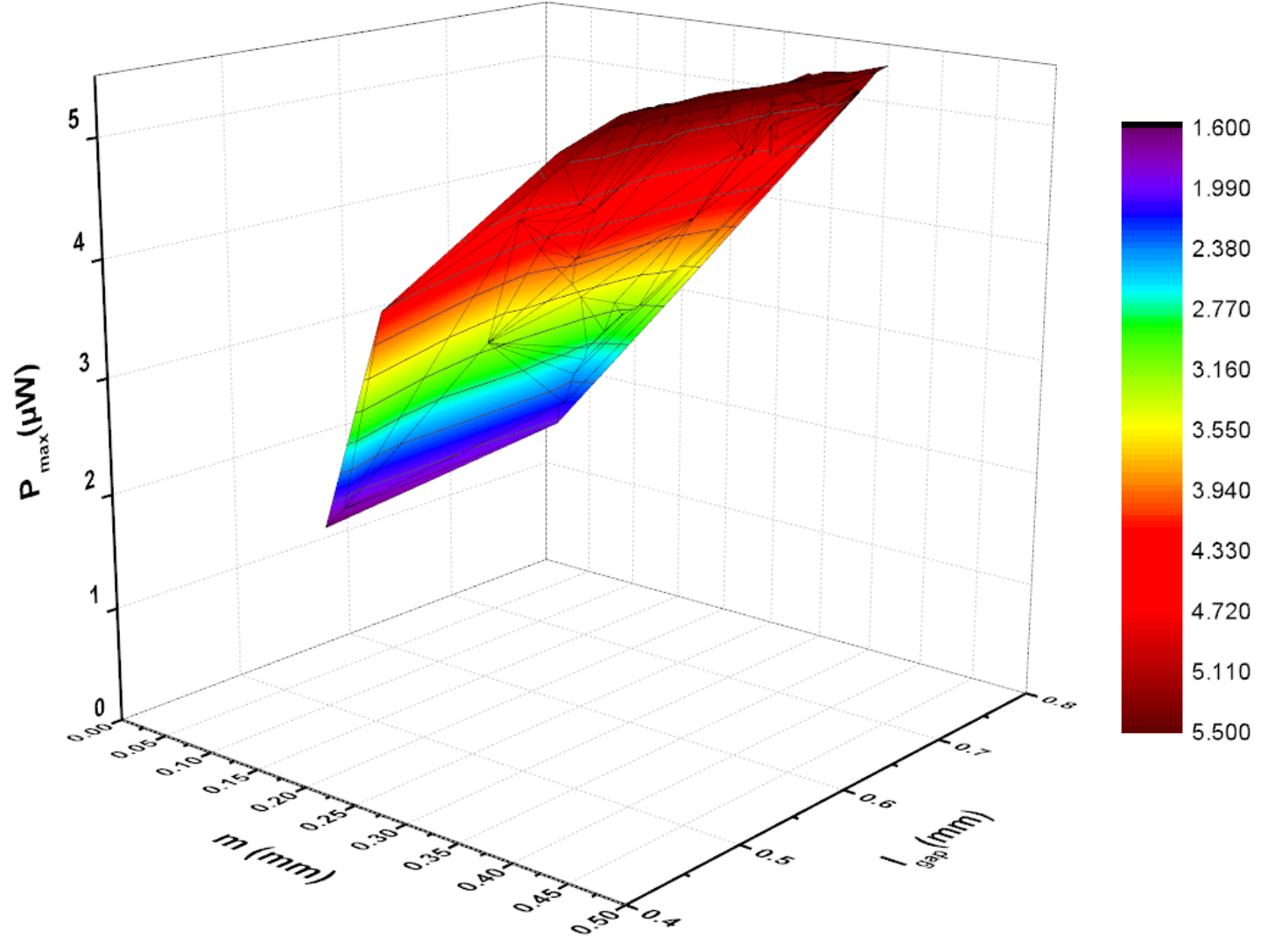

Figure 9 
a)

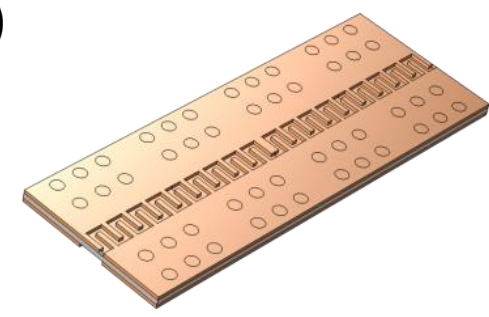

Commercial, flexible PCBs strips with ENIG layer on the Cu parts

TE materials sputtering and annealing

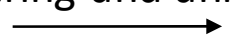

f)

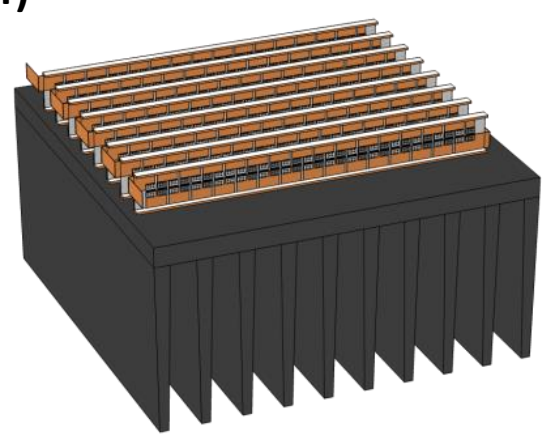

System assembly

e)

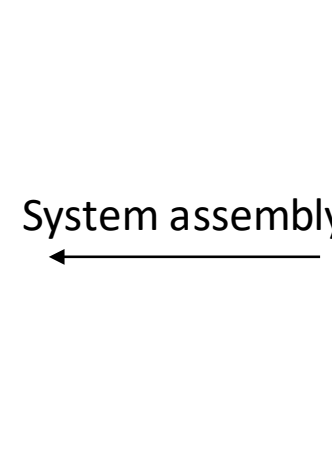

b)

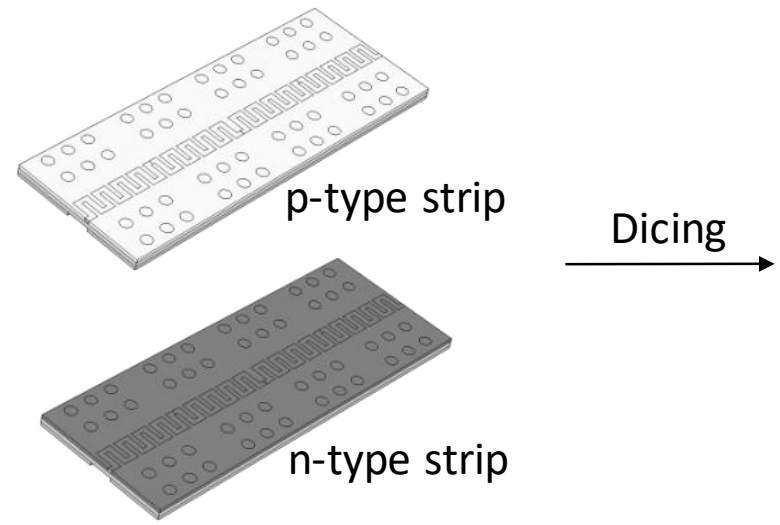

c)

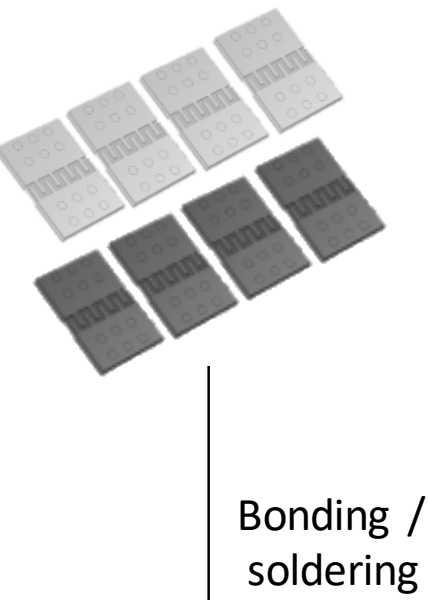

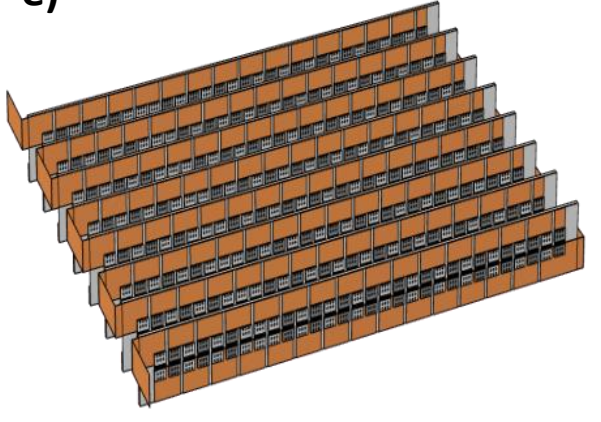

d)

TEG assembly

Figure 10 
a)

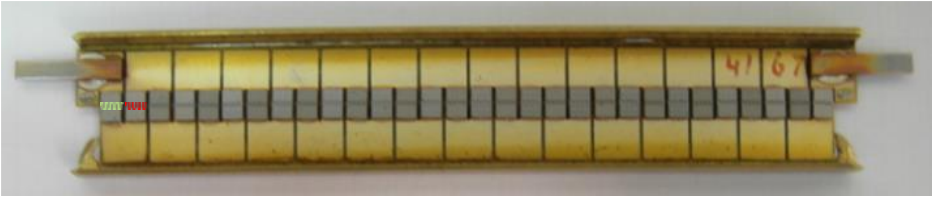

— $p$-type leg b)

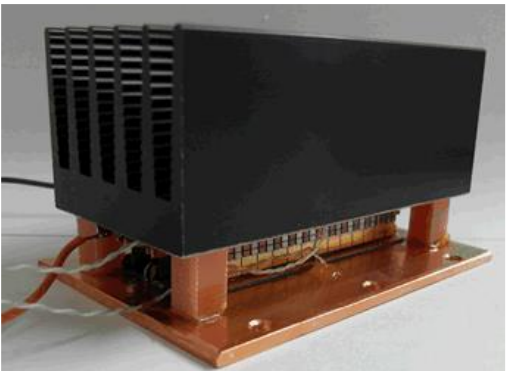

c)

Figure 11 
a)

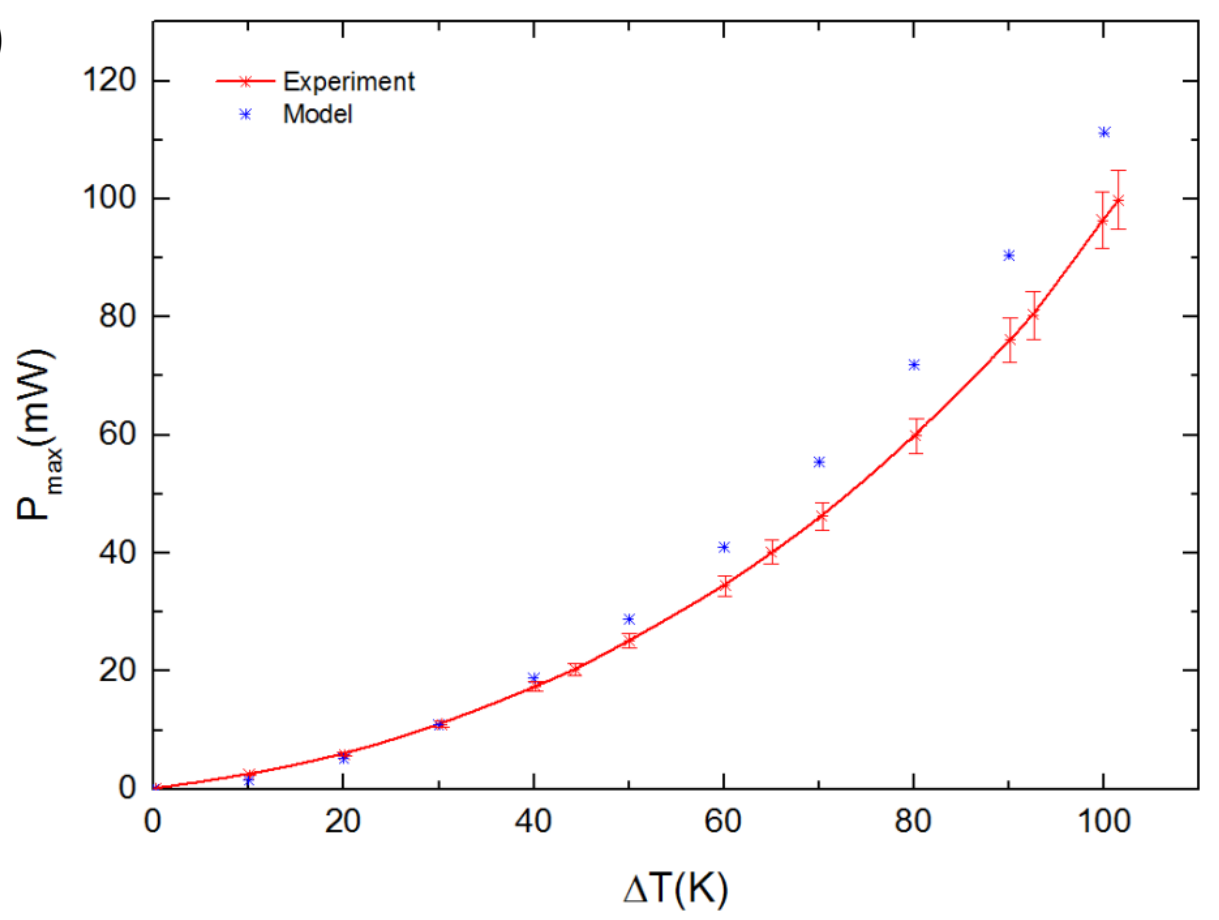

b)

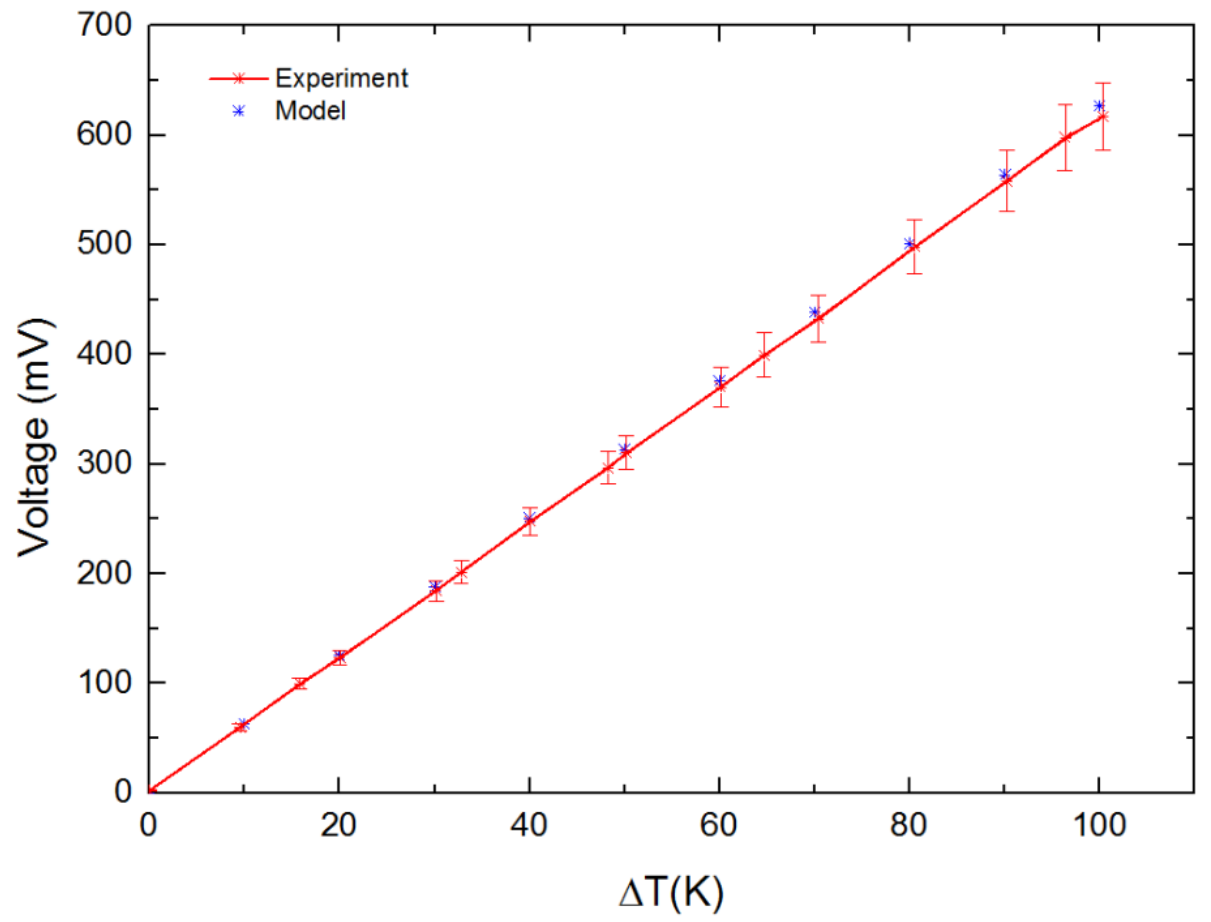

Figure 12 


\section{Table of Contents Entry}

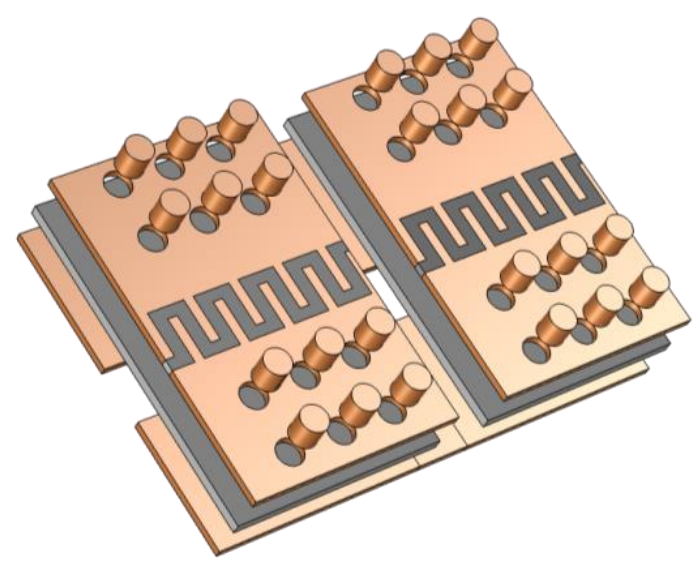

An innovative design of a thermoelectric micro-generator with integrated wavy-shaped $\mathrm{Bi}_{2} \mathrm{Te}_{3}-$ based materials yields the highest output power achieved so far for an in-plane device. 